\title{
Proposed Method for Determining the Thickness of Glass in Solar Collector Panels
}

Donald M. Moore

March 1, 1980

Prepared for

U.S. Department of Energy

Through an agreement with

National Aeronautics and Space Administration

by

Jet Propulsıon Laboratory

California Institute of Technology

Pasadena, California

(JPL PUBLICATION 80-34) 


\section{iVASTER}

\section{Proposed Method for Determining the Thickness of Glass in Solar Collector Panels}

Donald M. Moore

March 1, 1980

Prepared for

U.S. Department of Energy

Through an agreement with

Natıonal Aeronautics and Space Admınıstration

by

Jet Propulsion Laboratory

California Institute of Technology

Pasadena, Calıfornı

(JPL PUBLICATION 80-34)

This book was prepared as an account of work sponsored by an agency of the Unifed Stares Government Ne ther the United States Government nor any dyency thereof nor any of therr employees makes any

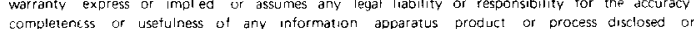
represents tha* its etse would nol nifringe privately owned rights Reference heren to any spec fir commercial product process or service by trade name trademark manufacturer or otherwise does not necessarily constitute or imply its endorsement recommendation or favoring by the Unted States Government or any aqency thereof The views and opinions of authors expressed herein do not necessarly state or reflect those of the United States Government or any agency thereo 


\section{DISCLAIMER}

This report was prepared as an account of work sponsored by an agency of the United States Government. Neither the United States Government nor any agency Thereof, nor any of their employees, makes any warranty, express or implied, or assumes any legal liability or responsibility for the accuracy, completeness, or usefulness of any information, apparatus, product, or process disclosed, or represents that its use would not infringe privately owned rights. Reference herein to any specific commercial product, process, or service by trade name, trademark, manufacturer, or otherwise does not necessarily constitute or imply its endorsement, recommendation, or favoring by the United States Government or any agency thereof. The views and opinions of authors expressed herein do not necessarily state or reflect those of the United States Government or any agency thereof. 


\section{DISCLAIMER}

Portions of this document may be illegible in electronic image products. Images are produced from the best available original document. 
Prepared by the Jet Propulsion Laboratory, Calıfornia Institute of Technology, for the Department of Energy through an agreement with the National Aeronautics and Space Administration

The JPL Low-Cost Solar Array Project is sponsored by the Department of Energy (DOE) and forms part of the Solar Photovoltarc Conversion Program to initiate a major effort toward the development of low-cost solar arrays

This report was prepared as an account of work sponsored by the United States Government Neither the United States nor the United States Department of Energy, nor any of their employees, nor any of therr contractors, subcontractors, or their employees, makes any warranty, express or implied, or assumes any legal lability or responsibility for the accuracy, completeness or usefulness of any information, apparatus, product or process disclosed, or represents that its use would not infringe privately owned rights 
ABSTRACT

As part of the Jet Propulsion Laboratory's Low-cost Solar Array Project, an analytical method has been developed for determining the minimum thickness for simply supported, rectangular glass plates subjected to uniform normal pressure environmental loads such as wind, earthquake, snow, and deadweight. The method consists of comparing an analytical prediction of the stress in the glass panel to a glass breakage stress determined from fracture mechanics considerations. Based on extensive analysis using the nonlinear finite element structural analysis program ARGUS, design curves for the structural analysis of simply supported rectangular plates have been developed. These curves yield the center deflection, center stress and corner stress as a function of a dimensionless parameter describing the load intensity. Results are included for plates having length-to-width ratios of $1,1.5,2,3$ and 4 . The load range considered extends to 1000 times the load at which the behavior of the plate becomes significantly nonlinear. Over the load range analyzed, the analysis shows that the ratio of center deflection to plate thickness for a plate of length-to-width ratio of 4 is less than 70 to 1 , whereas linear theory would predict a center deflection about 1200 times the plate thickness. The stress is also markedly lower than would be predicted by linear theory. These analytical results show good agreement with the analytical and experimental work of others.

A method of estimating the glass breakage stress as a function of a specified failure rate, degree of glass temper, design life, load duration time, and panel size is presented. Development of this method consisted largely of collecting and/or adapting, in convenient form, the best available information from the literature. To establish the glass breakage stress versus probability of failure, the experimental data of other investigators has been reanalyzed to obtain a "best-fit" Weibul1 statistical distribution. This state-of-the-art analysis yields the glass breakage strength as a function of failure probability.

A step-by-step procedure is given which includes determination of the applied stresses, glass breakage stress, and criteria for comparing the applied stresses to the estimated glass breakage stress. Errors in the method for determining the applied stress should be largely self-correcting, since this same method has been used to convert the glass plate burst pressure data of various investigators to the glass breakage stress reported herein. The results of this analysis indicate whether or not an assumed glass thickness will withstand the design loads at a failure rate specified by the designer. Finally, a sample problem is presented in Appendix I. 
The author would like to thank the following individuals who reviewed the October 1978 draft of this report: James Arnett, Robert Bamford, Rona1d Ross, all of the Jet Propulsion Laboratory, Alan Dalgliesh of the National Research Council of Canada, W. Lynn Beason of Texas Technical University, and Robert Stuart of the Pittsburg Plate Glass Company. Many of the reviewers' comments have been incorporated herein. In particular, the comments of $W$. Lynn Beason and Alan Dalgliesh led to significant improvements in the October 1979 draft of this report. In addition, the work described in this report was presented in October 1979 at a conference of window glass researchers held at the Institute for Disaster Research, Texas Tech University, Lubbock, Texas. Certain improvements in this version of the report are a result of that meeting. In particular, Robert Stuart of Pittsburg Plate Glass Company pointed out an error in the treatment of the strength of tempered glass which has been corrected.

I would also like to recognize the following individuals for specific contributions noted below. Parvis Sharifi of Merlin Technologies counseled me in the use of the ARGUS nonlinear finite element structural analysis program. Michael Giovan of the Jet Propulsion Laboratory performed the Weibull statistical analysis of the glass fracture data in the earliest draft of this report. Robert Weaver of the Jet Propulsion Laboratory wrote a FORTRAN computer program to automate the Weibull analysis. This program was employed to perform the more extensive analysis of glass plate burst pressure data contained in the October $1979 \mathrm{draft}$ and in this final report. 
I. INTRODUCTION - 1-1

II. FAILURE OF GLASS -

III. OVERVIEW OF PROPOSED METHOD -

IV. CAVEATS -- 4-1

V. STRESS ANALYSIS -

A. NONLINEAR FINITE ELEMENT ANALYSIS -

B. DIMENSIONLESS PARAMETERS -

C. CENTER DEFLECTION VERSUS LOADING - 5-4

D. STRESS VERSUS LOADING - 5-6

E. DESIGN CURVES FOR STRESS VERSUS LOADING - 5-10

VI. ALLOWABLE STRESS FOR GLASS - 6-1

A. EFFECT OF TEMPER AND LOAD DURATION - 6-1

B. EFFECT OF PLATE AREA

C. BREAKAGE STRENGTH VERSUS

PROBABILITY OF FAILURE -

VII. METHODOLOGY - 7-1

A. DEFINE THE LOADING - 7-1

B. ESTIMATE THE STRESSES - 7-3

C. DETERMINE THE ALLOWABLE STRESS FOR GLASS -

D. COMPARE APPLIED STRESS TO GLASS

BREAKAGE STRESS -

VIII. CONCLUSIONS AND RECOMMENDATIONS -

REFERENCES - 
APPENDIXES

I. SAMPLE PROBLEM -

II. LISTING AND SAMPLE OUTPUT OF FORTRAN COMPUTER

PROGRAM TO AUTOMATE BEST FIT WEIBULL ANALYSIS OF

GLASS PLATE BREAKAGE DATA -

Figures

1. Diagrammatic Representation of Proposed Glass

Thickness Sizing Method 3-1

2. Simply Supported, Rectangular Plate Subjected to

a Uniform Normal Pressure Load -

3. Finite Element Models of Rectangular Plates ----------- 5-3

4. Center Deflection $\div$ Thickness versus Load Intensity

Factory for Uniformly Loaded, Simply Supported

Rectangular Plates --_- 5-5

5. Stress Intensity Factor versus Load Intensity

Factor for Maximum Positive Principal Stress at

the Bottom Center of the Plate

$5-8$

6. Stress Intensity Factor versus Load Intensity

Factor for Maximum Positive Principal Stress at the Top Surface of the Plate in the Proximity

of the Corner -

7. SIF versus LIF Showing Composite Curves of the

Larger of the Maximum Positive Principal Stresses on

Plate (Center Bottom or Top Surface Near Corner) ---------- 5-11

8. Stress-Time Characteristics of Glass Broken in

Flexure Tests at Room Temperature (Composite Curves) ------- 6-2

9. Fraction of 1-Minute Load Duration Glass Breakage

Stress versus Load Duration

$6-4$

10. Fraction of Breakage Strength of 1-Square-Meter

Glass Plates versus Plate Area $6-5$

11. Breakage Strength versus Probability of Failure

for Simply Supported, Glass Plates Subjected to a Uniform Normal Pressure (Normalized to $1 \mathrm{~m}^{2}$ Surface Area and 1-Minute Load Duration) 6-23 
12. Recommended Design Values for Breakage Strength versus Probability of Failure for $1 \mathrm{~m}^{2}$, Simply Supported, Glass Plates Subjected to a Uniform Norma1 Pressure Load of 1-Minute Duration - 6-25

13. Cross-Section through Typical Sandwich-Type Photovoltaic Pane1

Tables

1. Data for New Annealed Plate Glass -

2. Data for New Annealed Sheet Glass

3. Data for Weathered Annealed Sheet Glass (weathered side in tension)

4. Data for Weathered Annealed Sheet Glass (0.219 x $28.5 \times 28.5$ inches - weathered side in tension) - -

5. Data for Weathered Annealed Sheet Glass $(0.219 \times 28.5 \times 60.5$ inches - indoor side in tension) - - 6-11

6. Data for Weathered Annealed Sheet Glass

$(0.219 \times 28.5 \times 28.5$ inches - indoor side in tension) ----- 6-12

7. Data for New Tempered Float Glass -

8. Normalized Breakage Stress for New Annealed Plate Glass -

9. Normalized Breakage Stress for New Annealed Sheet Glass -

10. Normalized Breakage Stress for Weathered Annealed Sheet Glass $(0.219 \times 28.5 \times 60.5$ inches weathered side in tension)- 6-18

11. Normalized Breakage Stress for Weathered Sheet Glass $(0.219 \times 28.5 \times 28.5$ inches weathered side in tension) 6-18

12. Normalized Breakage Stress for Weathered Annealed Sheet Glass $(0.219 \times 28.5 \times 60.5$ inches indoor side in tension) $6-19$

13. Normalized Breakage Stress for Weathered Annealed Sheet Glass $(0.219 \times 28.5 \times 28.5$ inches indoor side in tension)

14. Normalized Breakage Stress for New Tempered Float Glass 


\section{SECTION I}

\section{INTRODUCTION}

The need for a straightforward method of determining the glass thickness required for solar collector panels is evident. These panels are subjected to environmental loads which may be characterized as uniform normal loads (wind, earthquake, ice, snow and deadweight). Currently, the sizing of rectangular glass windows for uniform pressure loads is based largely on design curves available from glass manufacturers. These curves show the glass thickness versus window area required to sustain a given windload with a failure rate of 8 windows per 1000. These design curves are based on an empirical equation of the form

$$
P=k\left(t+t^{2}\right)
$$

where $P$ is the total load, $t$ is the thickness, and $k$ is an empirical constant. Empirical equations of this type have been developed by orr (Reference 1) and others. The application of this method for determining the thickness required for glass in solar collector panels has several shortcomings:

(1) Since relatively few samples of any particular size and thickness were tested (Reference 1 ), the resulting design curves do not have a strong statistical base. Statistically significant sample sizes are known to be important when dealing with brittle materials, such as glass.

(2) Loading was applied incrementally (Reference 1), and each load increment was held constant between 5 and 25 minutes while deflection, curvature and strain measurements were taken. Consequent1y, the load-time history at fracture for the various panels is not known. As will be seen later, the breakage strength of the glass depends on the load duration time.

(3) Because solar collector panels are tilted with respect to the horizon, loads such as snow and deadweight are applicable to the design of photovoltaic panels. Such loads, however, are not necessarily important factors in the design of ordinary windows. Because these loads are of longer time duration than wind loads, they will cause failure at a lesser applied stress, and therefore require special consideration in determining the required glass thickness.

It should be pointed out that since the above reservations concerning current methods for sizing rectangular windows were enumerated, the Pittsburg Plate Glass Company has published an improved glass thickness selection method entitled "Glass Thickness Recommendations to Meet Architects Specified 1-Minute Wind Load" 
(April 23, 1979). PPG's new method is soundly based on the same fundamental method of structural analysis that is used in this report: comparing a calculated applied stress to the allowable strength for glass. PPG also uses nonlinear finite element stress analysis to obtain an accurate estimate of the applied stress. However, the scope of the above document is. 1imited; their glass thickness recommendations are for wind loads of 1-minute duration and a failure rate of 8 windows per 1000 at the design load. 
Weiderhorn (Reference 2) has estimated that the theoretical cohesive strength of silica glass is of the order of $3 \times 10^{6}$ psi. The highest measured values for the strength of glass (glass fibers tested in a vacuum) approach this value. On the other hand, values normally associated with the engineering or practical strength of glass are approximately 10 to 1000 times lower than the theoretical cohesive strength. This discrepancy between the theoretical and the practical strength of glass is attributable to the brittle nature of the material. Stress concentrations at the tips of existing flaws, especially surface flaws, are not relieved by plastic yielding of the material. For this reason glass always fails in tension when these flaws grow (under sustained loading) to some critical size. Thus, the surface condition of the glass is the most important single factor influencing the breakage strength of any glass part. The following factors are known to materially influence the practical strength of glass parts.

1. Part Size. Even though the intrinsic strength of glass does not vary with part size, small glass parts (glass fibers, for example) exhibit strengths very much higher than relatively larger parts. Large parts have more and larger flaws, increasing the probability that a severe flaw will coincide with a region of high tensile stress. This phenomenon leads to a lower breakage strength for larger glass parts.

2. Moisture. Glass parts which have been dried and tested in a vacuum exhibit higher strengths than those tested in the presence of moisture. This behavior has been predicted from the "stress corrosion theory." It is important to note that the small amount of moisture normally present in the atmosphere is sufficient to account for most of this effect. Therefore, it will not be necessary to differentiate between the strength of glass parts in wet versus dry atmospheric conditions during normal outdoor exposure.

3. Surface Damage. The strength of glass parts may be expected to deteriorate with time due to environmentally induced damage resulting from handling, shipping, installation, cleaning, hail and rock impact, sandstorms and other causes. Dalgliesch and Beason (References 3 and 4) have indicated that there is evidence of a reverse effect as well in which severe stress concentrations at the tips of sharp microcracks are supposedly alleviated by rounding off those cracks for which the stress corrosion is not made highly directional by a large applied stress.

4. Duration of Load. Glass parts will sustain loads for short periods of time which will result in eventual failure. The existing flaws in the glass grow under the influence of a sustained load. When these cracks reach some critical size, failure occurs. 
The shortcomings of existing methods of determining the required thickness for simply supported, rectangular glass panels subjected to uniform normal pressure loads have already been noted. The existing methods are based on experimental burst pressure data for glass of various sizes and thicknesses, thus circumventing the need to predict the applied stress. The essence of the proposed method follows the conventional theme of structural analysis: applied stress is predicted as accurately as possible and subsequently compared to an allowable stress. The allowable strength will be based on those factors known to influence the breakage strength of glass: degree of temper, duration of the load, and size of the glass part. Additionally, the strength of the glass is treated in a probabilistic sense, so that the allowable strength is actually the glass breakage strength at a specified probability of failure. The proposed method is depicted graphically in Figure 1.

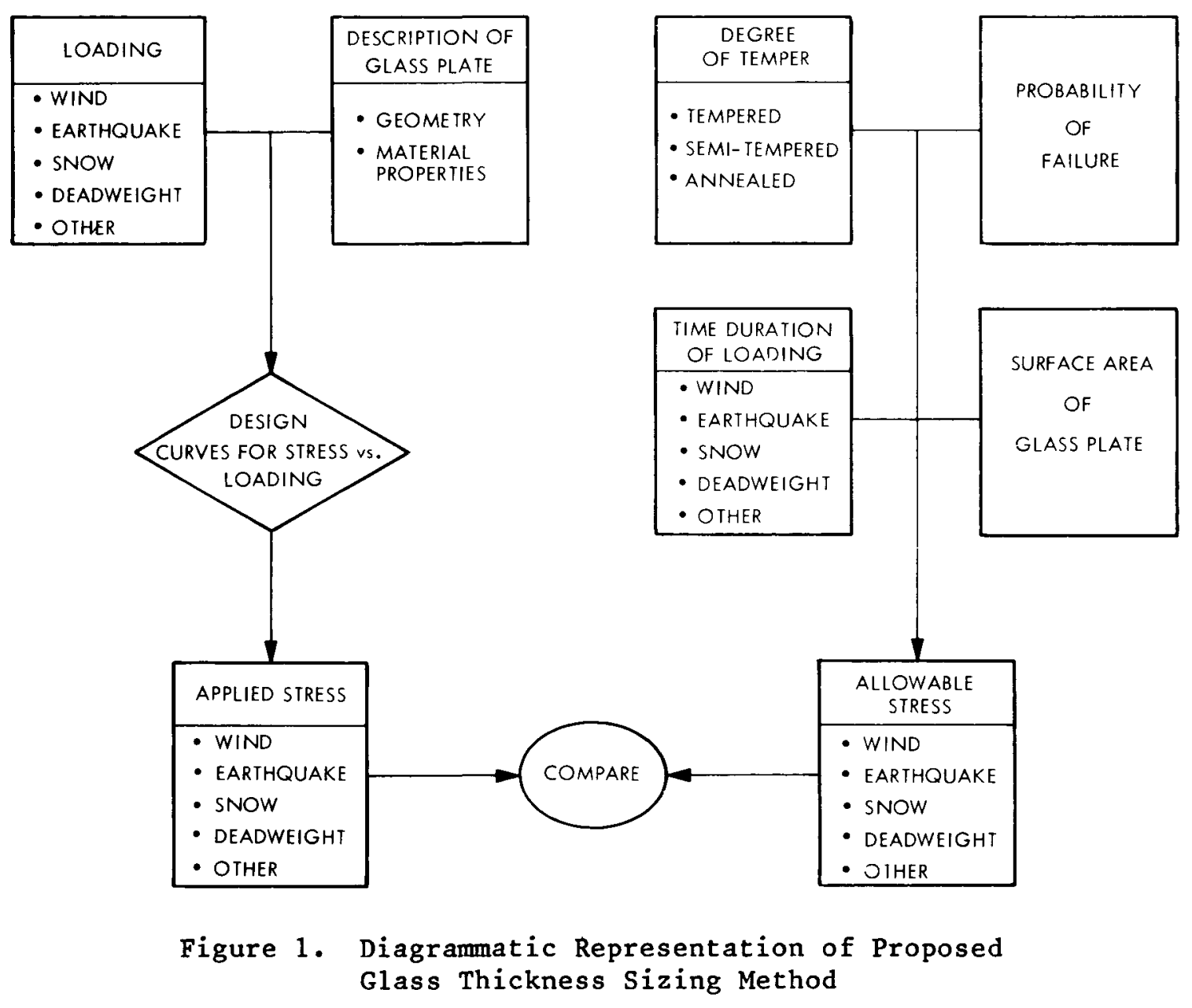


In order to implement the proposed glass thickness sizing method the following steps were taken:

(a) A non1inear finite element analysis of simply supported, rectangular plates subjected to uniform normal pressure loads was performed over a wide load range for plates with length-to-width ratios of $1,1.5,2,3$ and 4 . The results of this analysis are presented in nondimensional nomograph form.

(b) Means to quantify the effect on glass strength of degree of temper, duration of loading, and size of glass plates have been adapted from the literature.

(c) The nondimensional design curves are used to convert the glass pressure burst data of various investigators to glass breakage stress. This procedure minimizes errors resulting from inaccuracies in the proposed method for estimating applied stress, since consistent errors exist in the glass breakage stress reported herein.

(d) Weibull statistical analysis has been performed on the extensive test data of Beason (Reference 5) and Bowles and Sugarman (Reference 6). These investigators performed burst pressure tests on annealed sheet and plate glass of various thicknesses and sizes. The results of this analysis give the strength of annealed glass versus expected failure rate.

(e) Additionally, Abraham Wilson (Reference 7) of the Jet Propulsion Laboratory has performed burst pressure tests on $48 \times 48 \times 0.125$ inch simply supported, tempered glass plates. The results of a Weibull statistical analysis of these data give the strength of 0.125 in.-thick tempered glass versus the expected failure rate.

The development of this methodology is discussed in the following sections. 
SECTION IV

CAVEATS

The proposed method is intended to aid the practicing professional engineer or architect in determining the glass thickness required for a solar collector panel for a given application. The method is based on state-of-the-art analytical techniques (nonlinear finite element analysis and Weibull statistical analysis). While the method is believed to be sound, the author cannot assume responsibility for any loss incurred as the result of failure of a glass part designed using this method. Limitations of the proposed method recognized at this writing are enumerated below.

(1) It is limited to rectangular glass panels which are simply supported (negligible inplane or rotational constraint) on a11 four edges. This limitation does not apply if the stress in the glass panel can be assessed accurately by other means.

(2) It is limited to those loading conditions which can be considered to be uniform normal loads, such as wind, earthquake, snow, and deadweight.

(3) It is not intended to cover localized impact loads, such as those resulting from hail or other missiles. For guidance in designing hail-resistant glass solar collector panels, the reader is referred to "Photovoltaic Solar Panel Resistance to Simulated Hail" (Reference 8).

(4) It does not cover thermally induced stresses. These might arise from differences in the thermal expansion coefficients of glass and its mounting frame, from uneven temperatures across the surface of the panel due to shading from the adjacent row(s) of panels, or from local temperature gradients attributable to back-biasing of damaged solar cells.

(5) It does not account analytically for deterioration of the strength of the glass with time resulting from handling, shipping, installation, cleaning, missile impact, and other environmentally induced damage. These effects cannot be assessed quantitatively at this time. On the other hand, the glass breakage data analyzed in Section VI, which include 20-year-old weathered glass samples, show that while the mean strength of weathered glass is less than that of new glass, the breakage strength for a $1 \%$ probability of failure is about the same. 


\section{SECTION V}

STRESS ANALYSIS

A good estimate of the stress in a uniformly loaded, simply supported glass plate is a necessary ingredient of the proposed method to determine the required thickness of the glass. It is well known that plates loaded normal to their plane develop substantial mid-plane membrane stresses at moderate loads. This results in a nonlinear stiffening effect as the plate is loaded beyond the point at which the center deflection is about one-half the plate thickness. The stress and deflection of plates laterally loaded at moderate to high loads are significantly lower than are predicted by the linear theory, which assumes that the lateral load is resisted by bending stresses only and does not include the stiffening effect of the membrane stresses developed as the plate deflects under load. In practice, a linear analysis of glass plates subjcted to normal loads results in an overly-conservative design; that is, the glass is thicker than necessary.

Existing analytical and experimental results reviewed by the author (References 6, 9, 10, 11 and 12) have one or more of the following limitations with regard to their usefulness to the designer:

(1) They refer to glass whose edges are not simply supported (i.e., free to rotate but not to slide in plane)

(2) Only one length/width ratio is considered

(3) They are not presented in dimensionless form

(4) Only a narrow load range is included

Therefore, a nonlinear stress analysis of simply supported, rectangular plates subjected to uniform normal pressure loads is required.

\section{A. NONLINEAR FINITE ELEMENT ANALYSIS}

To obtain a good estimate of the stress in simply supported, rectangular glass plates subjected to uniform normal pressure loads, an extensive nonlinear analysis was carried out using the ARGUS nonlinear structural analysis program (Reference 13). The following symbols are used in reporting the results of this analysis and throughout the report in calculating the stresses in a simply supported, rectangular plate subjected to a uniform normal pressure load.

$$
\begin{aligned}
& a=\text { length of plate } \\
& b=\text { width of plate } \\
& t=\text { thickness of plate } \\
& E=\text { Young's modulus of plate material }
\end{aligned}
$$




$$
\begin{aligned}
\nu & =\text { Poisson's ratio of plate material } \\
D & =\text { Flexural rigidity of plate } \\
& =\frac{E t^{3}}{12\left(1-v^{2}\right)} \\
\delta & =\text { center deflection of plate } \\
\sigma & =\text { maximum positive principal stress in plate }
\end{aligned}
$$

The maximum positive principal stress $(\sigma)$ is taken as the critical stress, since glass is a brittle material. Figure 2 shows a simply supported, rectangular plate subjected to a uniform normal pressure load and defines the coordinate system used.

Plates with length/width ratios of $1,1.5,2,3$ and 4 have been analyzed. This analysis has been carried out over a broad loading range, extending to 1000 times the loading for which the results become significantly nonlinear. The finite element models of plates analyzed showing the various length/width ratios are shown in Figure 3. Note that due to symmetry only the upper right quadrant of the plates is modeled.

In genera1, the more finely divided a finite element model is, the more accurate the results. However, making the grid finer increases analysis costs geometrically. Nonlinear analysis is relatively expensive in any case because it is really "piecewise linear;" that is, the load is applied in many sma11 increments. After each load increment the new deflected shape is used to reformulate the

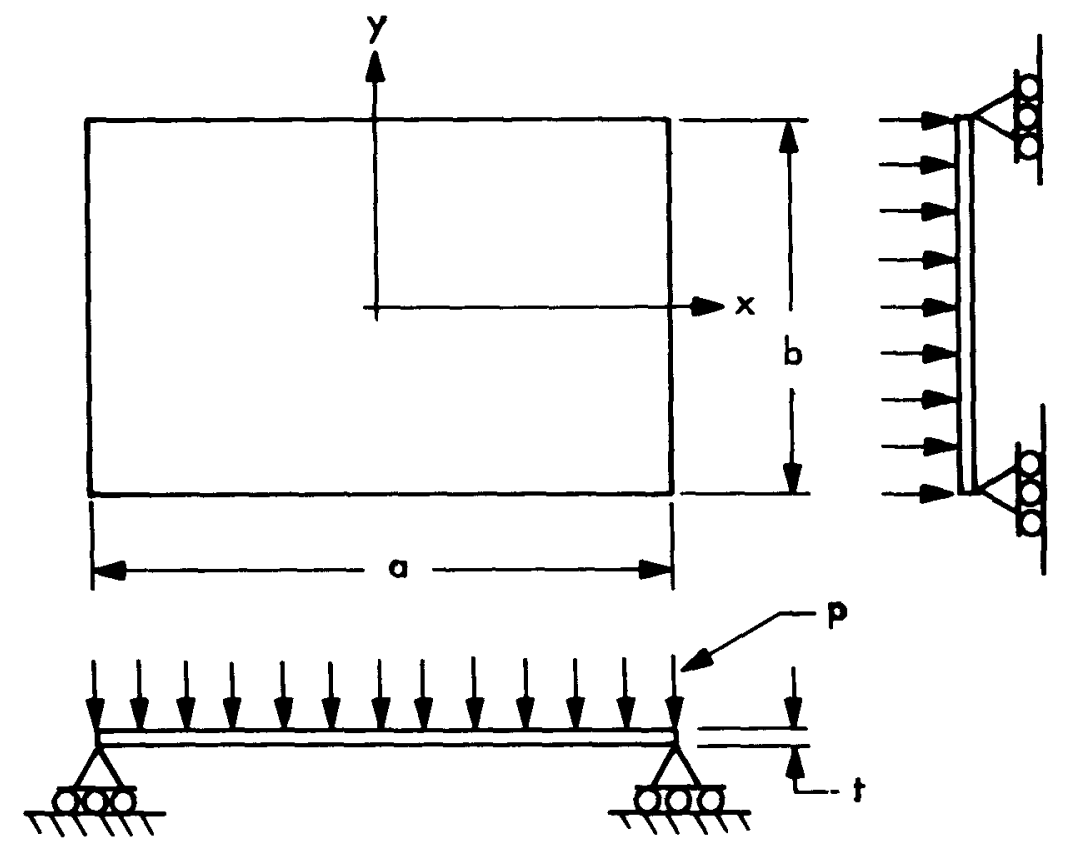

Figure 2. Simply Supported, Rectangular Plate Subjected to a Uniform Normal Pressure Load 


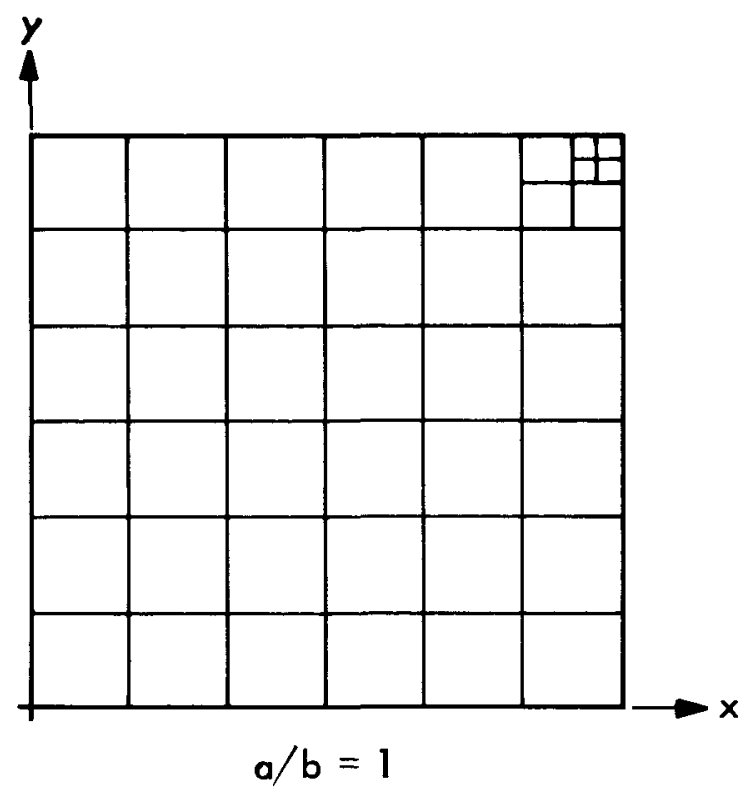

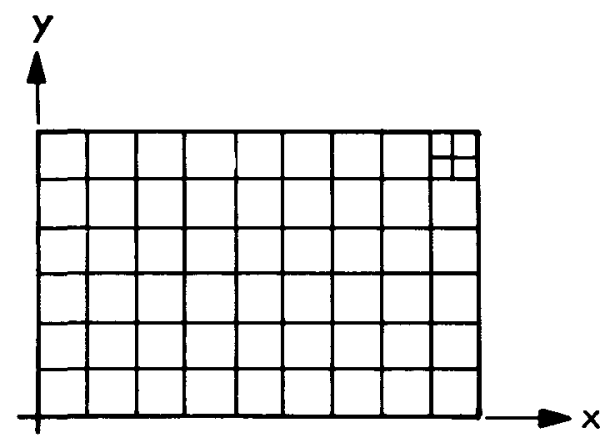

$a / b=1.5$

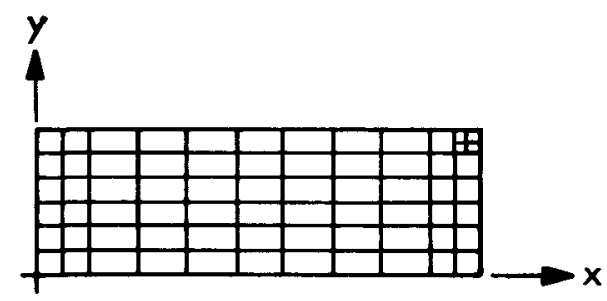

$a / b=3$

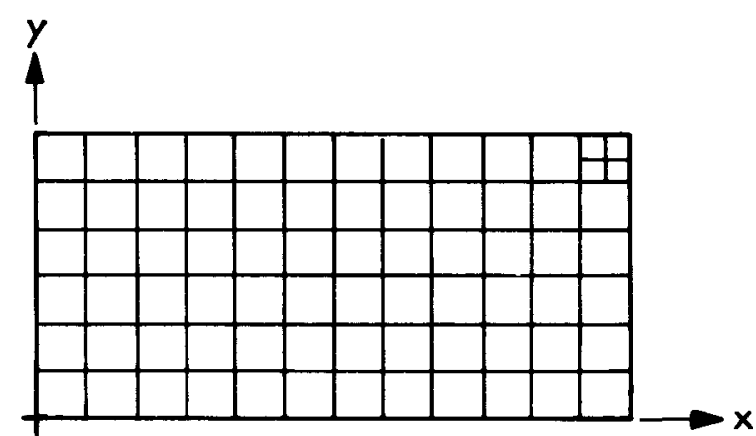

$a / b=2$

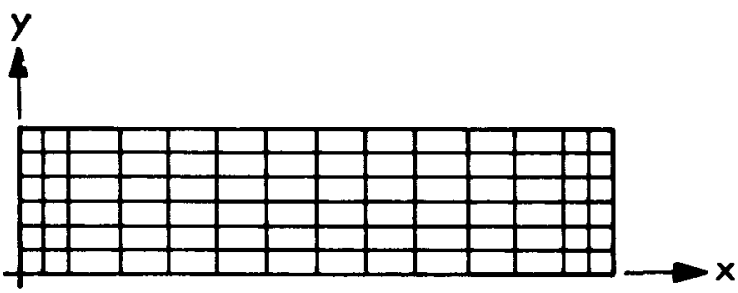

$a / b=4$

Figure 3. Finite Element Models of Rectangular Plates

stiffness matrix. The load increments must be small enough so that the linear analysis within each load increment properly accounts for the nonlinear stiffening effect resulting from the change in geometry of the deflected plate. If the total load range considered is high relative to the load at which the behavior of the plate becomes nonlinear, then a large number of load increments may be required, driving the cost upward. A broad load range in conjunction with a finely divided model, which increases the cost per load increment, may therefore make the analysis extremely expensive. 
The finite element models shown in Figure 3 yield reasonable accuracy at an affordable cost. Note that the grids shown are more finely divided at the corners of the plates where the stress gradient is highest. Even this improvement in the models incurred a cost penalty of the order of 50 percent.

Figure 3 indicates the relative size of the plates analyzed. The absolute size of the plates is inconsequential, since the results are reported in terms of dimensionless parameters which describe the load intensity, center deflection, and stress intensity.

\section{B. DIMENSIONLESS PARAMETERS}

The dimensionless parameter describing the relative severity of the loading is called the "load intensity factor" and is defined as

$$
L I F=\frac{p^{4}}{D t}
$$

The parameter used to "non-dimensionalize" the center deflection is the ratio of center deflection to plate thickness, that is

$$
\frac{\delta}{t}
$$

Finally, the "stress intensity factor" is defined as

$$
\operatorname{SIF}=\frac{\sigma b^{2} t}{D}
$$

\section{CENTER DEFLECTION VERSUS LOADING}

Figure 4 shows the present ARGUS results for the dimensionless center deflection, $\delta / t$, as well as the results from linear theory and the nonlinear analytical and experimental work of other investigators. The solid lines and dots show the results of the present nonlinear finite element analysis. The horizontal distance between two consecutive solid dots represents the amount of load applied during a particular load increment. The vertical distance between two consecutive dots represents the deflection that occurred during that load increment. The quantity of solid dots shown is reasonably representative of the minimum number of load increments which may be taken to obtain satisfactorily convergent results over the wide load range considered. The reader is reminded that the abcissa of Figure 4 is logarithmic, so the magnitude of the individual load increments may be continually increased as the total load increases. Smaller load increments are required for the rectangular plates of higher length/width ratios.

The present ARGUS results (dots) for rectangular plates of length/width ratios of 3 and 4 are not considered satisfactory at $\delta / t$ ratios above 40 . The reason for this problem is not known, but it is 


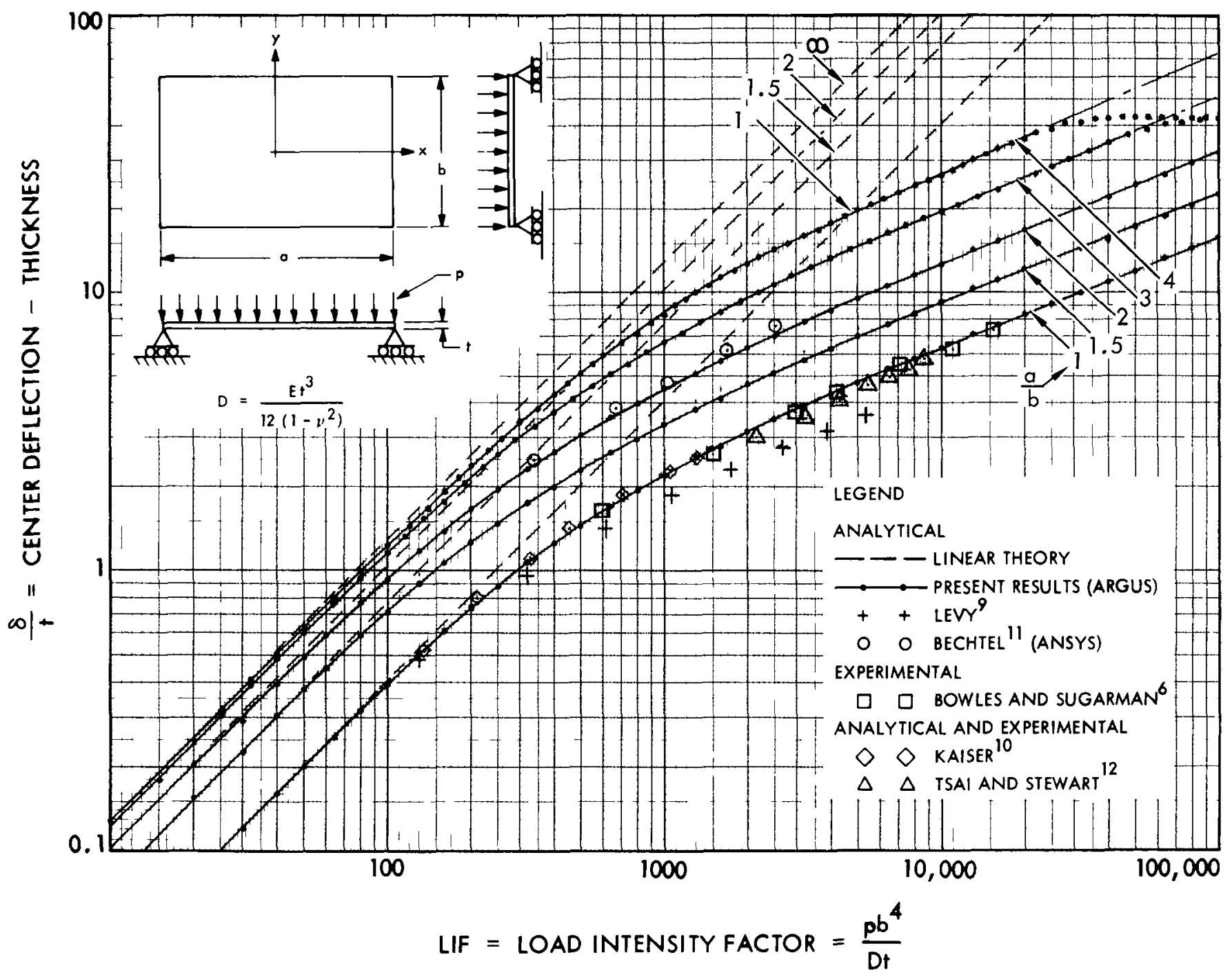

Figure 4. Center Deflection $\div$ Thickness versus Load Intensity Factor for Uniformly Loaded, Simply Supported Rectangular Plates 
suspected that cumulative errors due to the large number of load increments required (for length/width ratios of 3 and 4 ) have resulted in numerical problems. The recommended results in this region are shown by the dot-dash lines which are extrapolated from the results for $\delta / t$ less than 40 .

Excellent agreement of the present results with those predicted by linear theory is obtained for load intensity factor (LIF) values less than 50. In the nonlinear range, the current results for the center deflection of square plates are compared to the analytical results of Levy (Reference 9), the experimental results of Bowles and Sugarman (Reference 6 ), and the analytical results of Kaiser (Reference 10) and Tsai and Stewart (Reference 12). The current result for the center deflection of a square plate is about 25 percent higher than that of Levy at a load intensity factor (LIF) of 1280 . Levy's solution, based on a numerical solution of von Karman's equations in terms of trigonometric series, would appear to be applicable to the present problem. Beason has pointed out, however, that the edge conditions imposed by Levy are not identical to those imposed here. That is, while, the edges of Levy's plate were free to translate laterally, they were also constrained to remain straight when viewed normal to the $x-y$ plane. This accounts for the increased stiffness indicated by Levy's solution. In fact, Levy stated that Kaiser's solution for the center deflection at a load intensity factor of 1280 is about 25 percent higher than his own and that "this difference is probably due to the fact that Kaiser allows distortions of the edges of the plate." The current results for the center deflection of square plates are in excellent agreement with the experimental results of Bowles and Sugarman. It is interesting to note that each of the data points of Bowles and Sugarman represents the average center deflection at fracture reached by thirty 41-inch square glass plates of the same thickness. The 7 points plotted are for 7 different thicknesses and represent a total of 210 tests. The agreement with the analytical and experimental results of Kaiser, and Tsai and Stewart is also very good. Kaiser's analysis is based on a finite difference solution of the von Karman equations, while Tsai and Stewart employed finite element analysis. Nonlinear finite element analysis of the center deflection of a rectangular plate of length/width ratio of 2 , carried out by the Bechtel Corporation (Reference 11) using the ANSYS structural analysis program, is in excellent agreement with the current results.

The linear theory is inadequate to predict accurately the deflection of plates at moderate to high (100 to 100,000) load intensity factors (Figure 4). For a square plate at load intensity factor of 100,000 , linear theory predicts a deflection about 25 times that predicted by the present nonlinear finite element analysis.

\section{STRESS VERSUS LOADING}

Figures 5 and 6 show the relationship of non-dimensionalized stress to load (SIF vs LIF) obtained for the center and corner, respectively, of plates of various length/width ratios. The stress plotted is the maximum positive principal stress. 


\section{Center Stress}

Excellent convergence of the present results with those predicted by the linear theory is seen for load intensity factor (LIF) values less than 100 (Figure 5). In the nonlinear load range, the current results are in good agreement with the analytical and experimental work of Kaiser, and Tsai and Stewart for square plates. The current results average about 5 percent higher than the former and 13 percent higher than the latter. The present results for square plates are very nearly identical with the experimental results of Bowles and Sugarman. Levy's results for the center stress of square plates are also plotted for reference, even though his edge constraints differ from those considered here.

The present results for the center stress of a plate having a length-to-width ratio of 2 are in good agreement with Bechtel's analytical results and with Tsai and Stewart's analytical and experimental results, averaging about 6 percent lower than the former and 2 percent higher than the latter. For plates having a length-towidth ratio of 4 , only the analytical and experimental results of Tsai and stewart are available for comparison. Their results are virtually identical with the current results at the low values of load intensity factor considered by them. As in the case of center deflection, the ARGUS results (dots) for the center stress for plates of length-towidth ratios of 3 and 4 are not considered satisfactory above load intensity factors of 50,000 and 30,000 respectively. The recommended results in this region are shown by the dot-dash lines which are extrapolated from the results for lower load intensities.

\section{Corner Stress}

The ARGUS structural analysis program yields the stresses at the center of the elements of the finite element models shown in Figure 3. Near the center of the plates the stress changes gradually with respect to position in the plate. Therefore, the stress at the center of the element nearest to the center of the plate was assumed to be the same as the stress at the center of the plate. Near the corners of the plate, however, the stress gradient is high and the peak stress in the proximity of the corner of the plates cannot be assumed to be the same as stress at the center of the element nearest the corner of the plate. The peak stress in the proxmity of the corners was obtained by a second order La Grangian interpolation or extrapolation of the stresses at the center of those three elements whose centers lie along a path estimated to contain the point of maximum positive principal stress. The maximum psoitive principal stresses so obtained occur at or near the corner of the plate at the upper surface of the plate in a very localized region which is convex upward. These results are plotted in Figure 6 . These results are in excellent agreement with the Bechtel analytical results for plates of length-to-width ratio of 2 , being about 6 percent lower on the average. The current results are an average of 1,12 and 8 percent lower than the analytical and experimental results of Tsai and Stewart for length-to-width ratios of 1,2 and 4, respectively. Again, the 


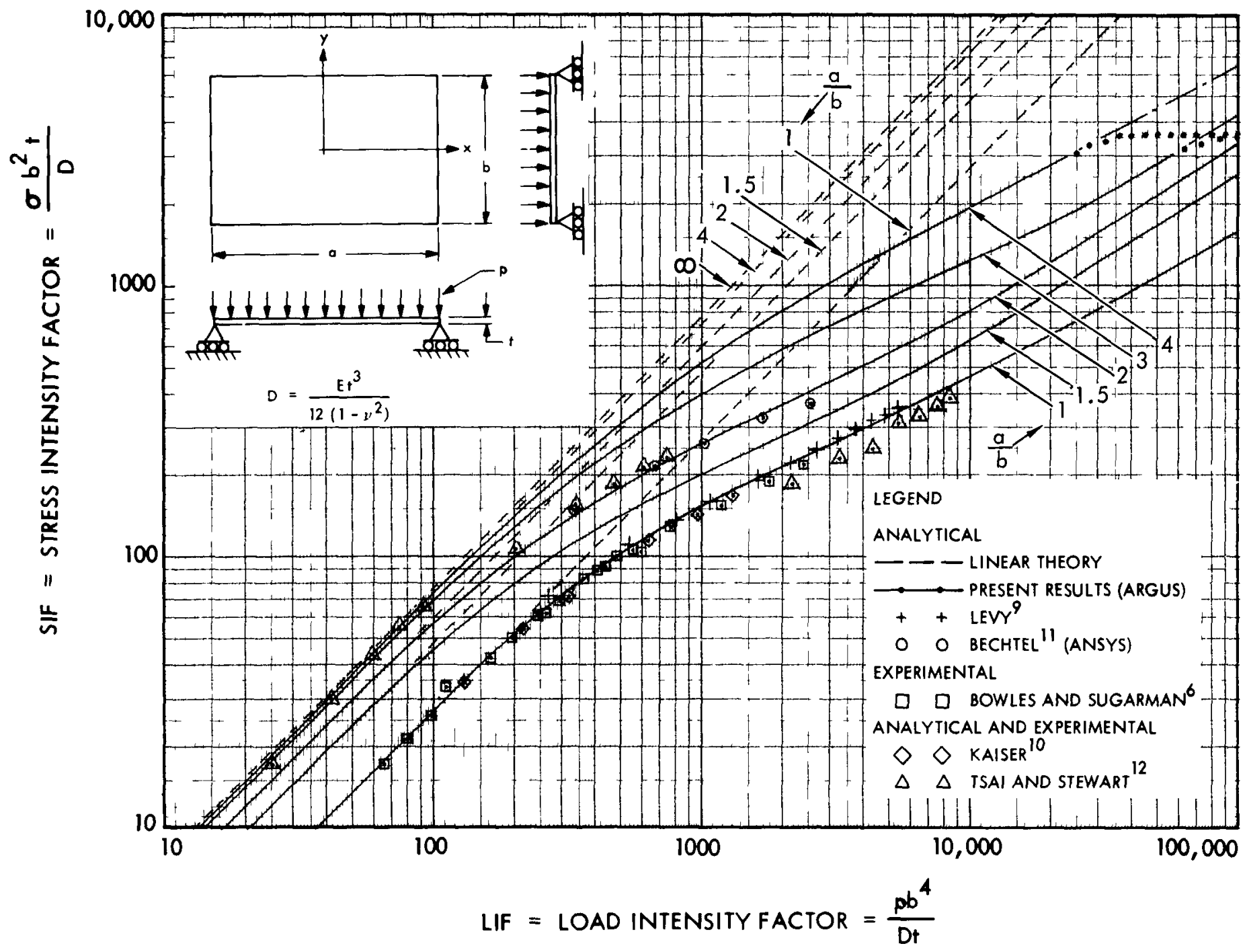

Figure 5. Stress Intensity Factor versus Load Intensity Factor for Maximum Positive Principal Stress at the Bottom Center of the Plate 


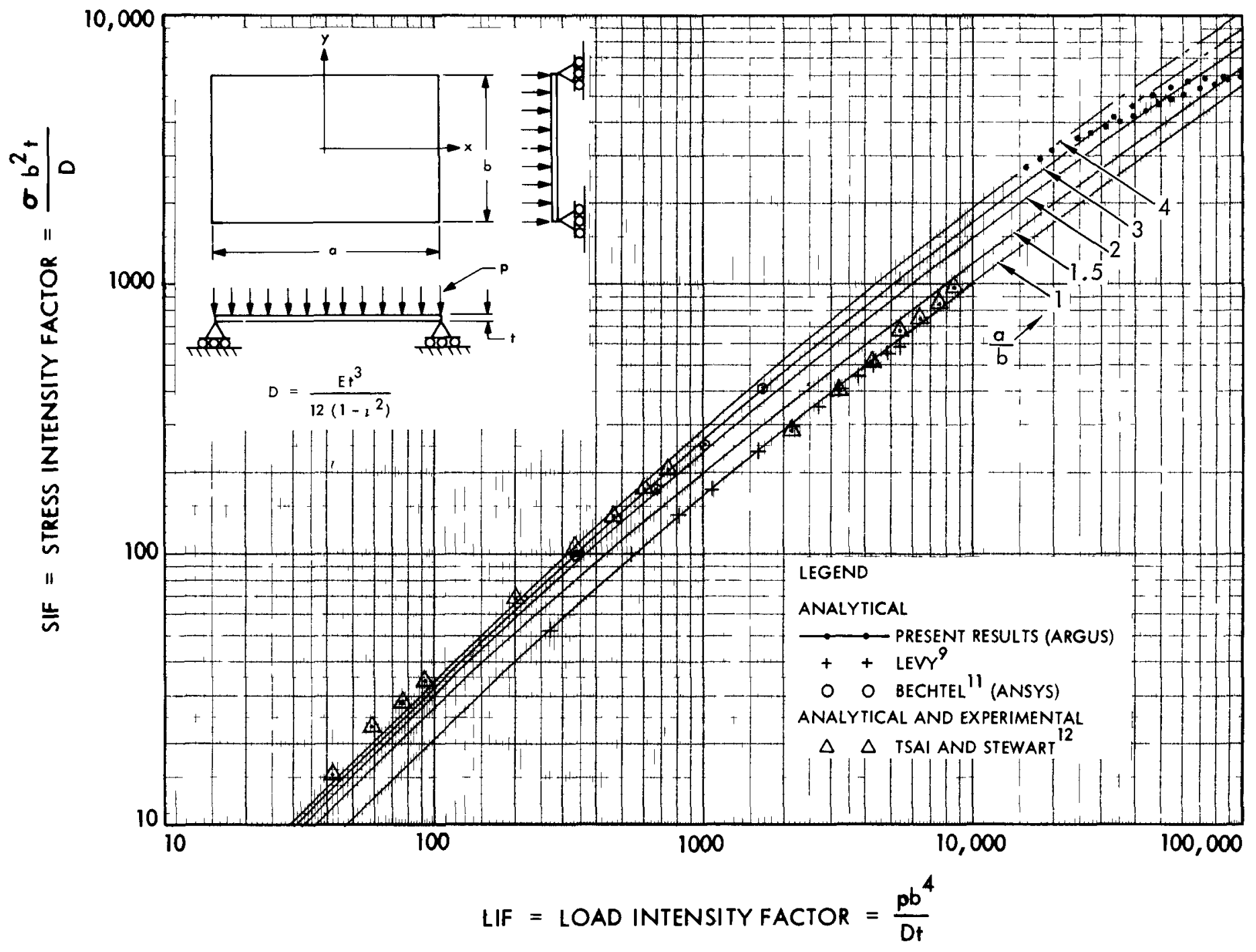

Figure 6. Stress Intensity Factor versus Load Intensity Factor for Maximum Positive Principal Stress at the Top Surface of the Plate in the Proximity of the Corner 
ARGUS results for length-to-width ratios of 3 and 4 are unsatisfactory above load intensity factors of 30,000 and 10,000 , respectively. Better values for the corner stress may be obtained by extrapolating the results for lower load intensities as shown by the dot-dash lines in Figure 6. Comparing Figures 5 and 6 , it is seen that the corner stress increases linearly with load to higher values of the load intensity factor than does the center stress. This relatively linear behavior of the corner stress is to be expected, since linear beahvior is associated with small deflections and the deflection in the close vicinity of the corner of the plates is comparatively small.

\section{E. DESIGN CURVES FOR STRESS VERSUS LOADING}

It can be seen (Figures 5 and 6 ), that stress at the center of the plates is higher than that at the corners of the plate for low to moderate loading. At higher loads, however, the stress at the corners of the plate is higher. Figure 7 is constructed by superimposing Figure 5 on Figure 6 , but showing only the higher of the center or corner stresses at any given load intensity. Figure 7 yields the maximum positive principal stress, $\sigma$, versus load intensity factor for length- to-width ratios of $1,1.5,2,3$ and 4 . The maximum positive principal stress occurs on the bottom surface of the plate at the center and on the top surface of the plate at the corners. At the center it is predominantly membrane tension stress plus bending stress. At the corners it is largely shear stress. 


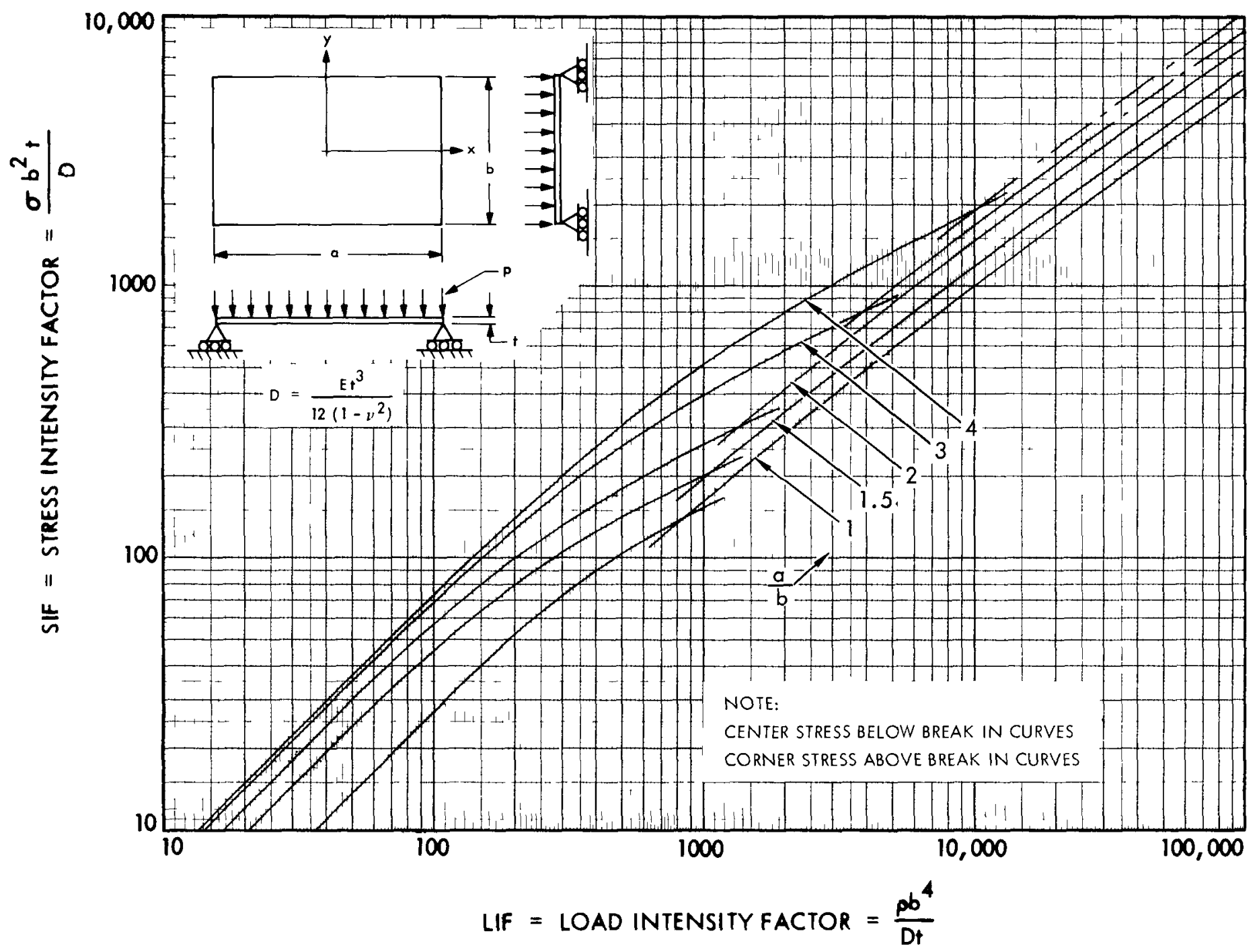

Figure 7. SIF versus LIF Showing Composite Curves of the Larger of the Maximum Positive Principal Stresses on Plate (Center Bottom or Top Surface Near Corner) 


\section{SECTION VI}

\section{ALLOWABLE STRESS FOR GLASS}

A brief discussion of the factors influencing the failure of glass, adapted from Brown (Reference 14), is included here. In 1921 Griffith noted the weakening effect of preexisting flaws or scratches in the glass surface. The high stresses at the tips of these flaws account for the fact that the measured strength of glass in tension is usually several orders of magnitude lower than its theoretical strength. Deliberate surface conditioning of the glass surface by various investigators has borne out Griffith's observation. Surface roughening reduces the mean strength and variability. Polishing increases the mean strength and variability. The measured strength of glass samples tested in moist air decreases with increased duration of loading. It is now generally accepted that slow flaw growth takes place as a result of stress corrosion. The mathematical model describing the dependence of glass failure on load duration and loading proposed by Brown (Reference 14) has been adopted by Beason (Reference 4) and Dalgliesh (Reference 3) in the following form.

$$
\begin{aligned}
& \int_{0}^{\tau_{B}}[\sigma(\tau)]^{\alpha} d \tau=\text { constant } \\
& \text { where } \\
& \tau=\text { time } \\
& \tau_{B}=\text { time to break } \\
& \sigma(\tau)=\text { applied, time-variant stress } \\
& \alpha=\text { an empirically determined constant which depends on the }
\end{aligned}
$$

With these factors considered, a quantitative assessment of the effect of glass temper, time duration of loading, glass surface area, and probability of failure is presented in the following paragraphs.

\section{A. EFFECT OF TEMPER AND LOAD DURATION}

As discussed above, the breakage strength of glass decreases as the duration of loading increases. For a constant applied stress Equation 4 may be written in the form

$$
\sigma_{B} \propto\left(\frac{1}{\tau_{B}}\right)^{\frac{1}{\alpha}}
$$


where

$\sigma_{B}=$ breakage strength

$\tau_{\mathrm{B}}=$ time to break

$\alpha=$ an empirically determined constant, applicable only over a narrow range of load durations where it fits the data.

Dalgliesh (Reference 15) reports values of $\alpha$ for annealed glass from 12 to 20. Dalgliesh does not recommend a value of $\alpha$ for tempered glass. Shand (Reference 16) states that not only is tempered glass stronger initially, but the decrease in the breaking strength of tempered glass with load time is significantly less than that for annealed glass. This implies that the value of $\alpha$ would be significantly higher than 20 .

For the simple power law (Equation 5) just discussed, the fracture stress approaches zero for loads of very long duration. This is at odds with the widely accepted idea that there is a level of applied stress, called the "endurance limit," below which crack growth will not occur. At levels of applied stress less than the endurance limit glass parts should be able to sustain loads for an indefinite period of time. Figure 8, reproduced from Shand (Reference 16), shows the breaking stress versus the duration of that stress. These curves are consistent with the concept of an endurance limit in that they tend toward some asymptotic lower bound of the breaking stress for long-term loading. Unfortunately, these curves extend only to a load duration of $10^{7}$ seconds (approximately 4 months), whereas to properly consider deadweight load, we need load durations up to the design life of the glass plates (that is, greater than 20 years). Also, it should be noted that Shand (Reference 16) does not specify the size of the glass specimens on which Figure 8 is based.

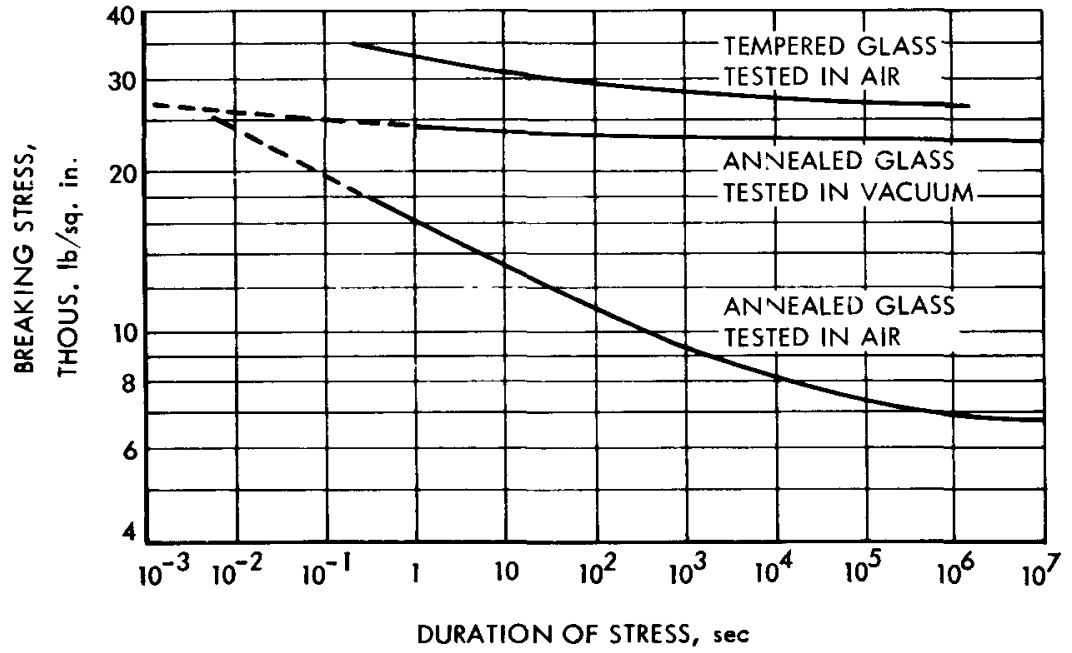

Figure 8. Stress-Time Characteristics of Glass Broken in Flexure Tests at Room Temperature (Composite Curves) 
Therefore, it is the relative strength of annealed glass versus tempered glass and the decrease in strength with time that are of interest here.

The curves shown in Figure 9 have been extrapolated to a load duration of approximately 100 years and normalized to a value of unity for the 1-minute breaking stress of the glass. Shand (Reference 16) has stated that the endurance limit for (annealed*) glass is of the order of 40 to 45 percent of the 5-second breaking strength. The curve for annealed glass (Figure 9) has been faired to a value of about 40 percent of the 5 -second breaking strength at 100 years load duration. This is somewhat less than if Shand's original curve (see dotted line - Figure 9) had been simply extrapolated to longer load durations. Likewise the curve for tempered glass shown in Figure 9 is somewhat lower at long load durations than Shand's original curve (shown dotted). To obtain strength-versus-time values for semi-tempered glass, the values for annealed and tempered glass have, arbitrarily, been averaged. The resulting values for semi-tempered glass are shown as a dot-dash curve in Figure 9. The equation $\mathrm{f}_{\mathrm{T}}=(1 / \tau)^{1 / 12}$ is also plotted in Figure 9 . This equation is equivalent to Equation 5 and shows that for load durations between 5 seconds and 1 minute the value of $\alpha$ equal to 12 provides an excellent fit to the annealed glass curve. Likewise, a value for $\alpha$ of 40 provides an excellent fit to the tempered glass curve for load durations between 5 seconds and 5 minutes.

\section{B. EFFECT OF PLATE AREA}

As mentioned earlier, large glass parts fail at lower applied stress levels than do small glass parts. This is true because the likelihood that a flaw in the glass will coincide with a region of high applied stress is greater for larger parts. These flaws exist in newly manufactured glass and their size and/or number increase with time due to handling, missile impact and other loads. In the vast majority of cases, failure originates from surface flaws so that the area of a glass plate represents the pertinent measure of part size. Dalgliesh (Reference 15) reported that laboratory tests on glass plates have shown that the breaking strength varies inversely as the fifth to seventh root of glass surface area.

$$
\sigma_{B} \propto\left(\frac{1}{A}\right)^{\frac{1}{6}}
$$

\footnotetext{
*It is assumed that Shand means annealed glass since he further states that the decrease in the breaking strength of tempered glass with increasing load duration time is significantly less than that for annealed glass.
} 


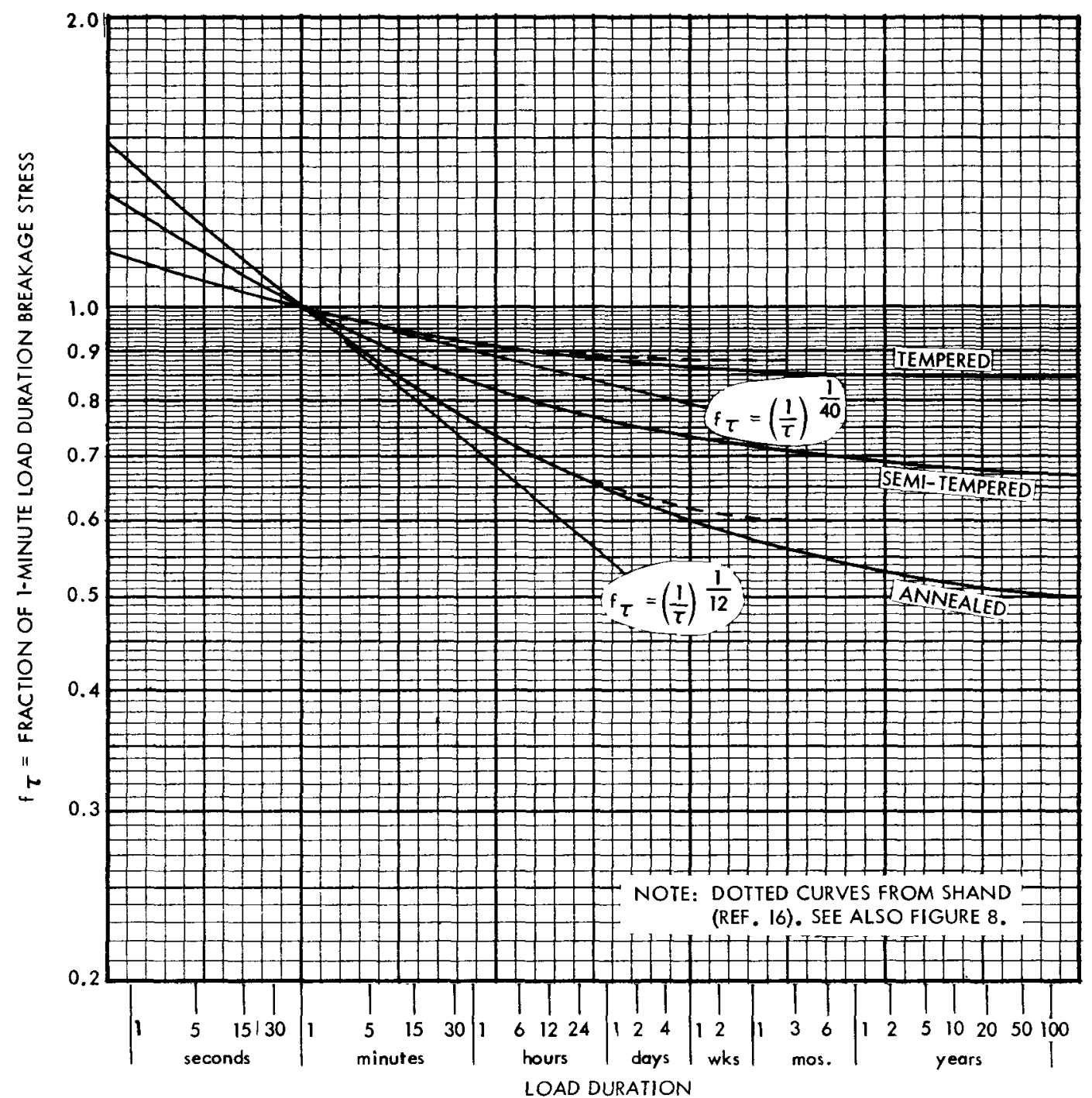

Figure 9. Fraction of 1-Minute Load Duration Glass Breakage Stress versus Load Duration

For the purpose of the design method presented herein, it is expedient to define the fraction, $f_{A}$, which is the fraction of the breaking stress of a 1-square-meter plate which will be attained by a plate of area $A$ if both plates break 1 minute after the sudden application of the full load. From Equation 5 the fraction $\mathrm{f}_{\mathrm{A}}$ may be expressed mathematically as

$$
f_{A}=\left(\frac{1}{A}\right)^{\frac{1}{6}}
$$

where

$f_{A}=$ fraction of the breaking stress of a 1 square meter plate which will be attained by a plate of area $A$

$A=$ area of plate for which breaking stress is unknown (expressed in square meters)

Equation 7 is plotted on Figure 10. 


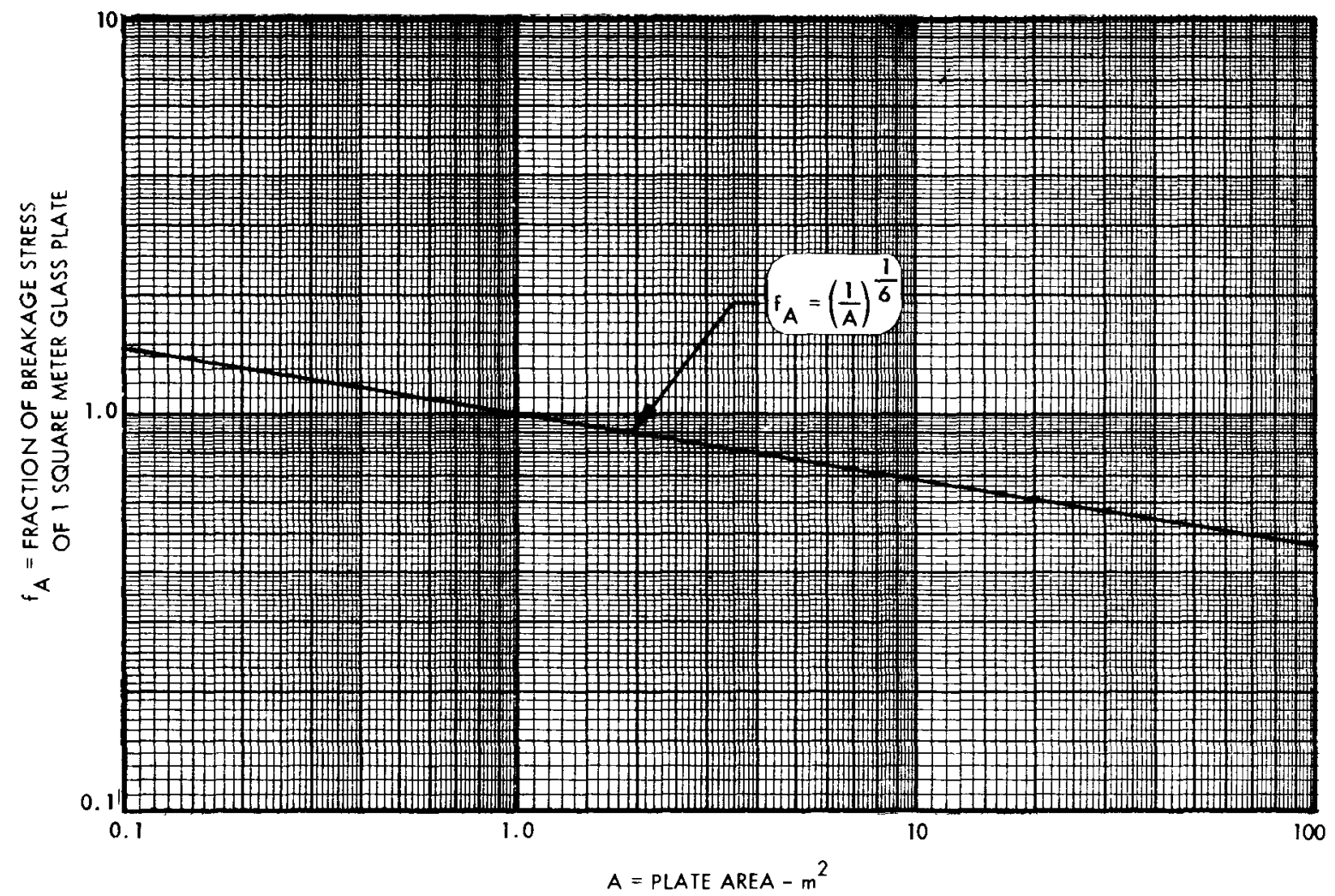

Figure 10. Fraction of Breakage Strength of 1-SquareMeter Glass Plates versus Plate Area

\section{BREAKAGE STRENGTH VERSUS PROBABILITY OF FAILURE}

In the following paragraphs the glass plate breakage data of other investigators is reanalyzed to obtain the glass breakage strength as a function of the probability of failure.

\section{Selection of Glass Plate Breakage Data}

To obtain a practical value for the breaking strength of glass to be used in determining the required thickness of photovoltaic solar panels the raw data of Bowles and Sugarman (Reference 6), Beason (Reference 5), and Wilson (Reference 7) have been analyzed employing Weibull statistical analysis techniques. The data of these investigators are preferred for the following reasons:

(a) The size of the samples tested is intermediate between the smallest and largest glass photovoltaic modules being considered. Bowles and Sugarman tested 41-inch square glass plates. Beason tested $28.5 \times 60.5$-inch plates and 28.5-inch square plates. Wilson tested 48-inch square plates. 
(b) These investigators employed edge constraints which approximate a simply-supported condition.

(c) The load-time history prior to panel failure is necessary to make a meaningful assessment of the breaking stress for other load-time histories. The load-time histories from these data sources are known reasonably well. Bowles and Sugarman loaded the panels with a pressure load which increased approximately as the second power of time. They adjusted the loading mechanism so that the average pressure resulting in failure was reached 30 seconds after the start of the test. Beason's raw data are more definitive in this respect. His data include a complete pressure-time history for each sample of glass tested, as does Wilson's.

(d) These investigators tested a sufficient number of samples for the results to be statistically significant. Bowles and Sugarman tested 40 samples of .122-inch-thick annealed plate glass, 30 samples each of $.197, .250, .373-$ inchthick annealed plate glass and $.110, .158, .195-$ inch-thick annealed sheet glass - all 41 inches square. Beason tested 20 samples each of $.219 \times 28.5 \times 60.5$-inch and .219 $x 28.5 \times 28.5-i n c h$ annealed sheet glass. In Beason's tests the 20 samples of each size were divided into 10 samples with the weathered side in tension and 10 samples with the indoor side in tension. Wilson tested 8 samples of $.125 \times 48 \times 48$-inch tempered float glass.

(e) The Bowles and Sugarman tests were performed on new annealed sheet and plate glass as noted above. Beason's tests were performed on "weathered" glass, removed from the Great Plains Life Building, Lubbock, Texas. This glass had been in service for about 20 years at the time of its removal for testing; it is believed to be annealed sheet glass. Wilson tested new tempered float glass.

Tables 1 and 2 give the burst pressure $\left(p_{B}\right)$ data for the Bowles and Sugarman tests of annealed plate glass and annealed sheet glass, respectively. These data were adapted from histogramic data included in the Bowles and Sugarman report. Tables 3, 4, 5 and 6 show the pressure-time history of Beason's tests of the 20-year-old weathered annealed sheet glass plates. Table 7 shows the pressure-time history of Wilson's tests of new tempered float glass.

\section{Normalizing the Glass Plate Breakage Data}

Examination of the data in Tables 1 through 7 shows that glass plates of various sizes break over a wide range of pressures after experiencing different pressure-time histories. It has already been noted that the breakage strength of glass is a function of the load duration and the surface area of the glass plate. 
Table 1. Data for New Annealed Plate Glass

Burst pressure data for 41-inch square, simply supported, new annealed plate glass plates (from Bowles and Sugarman -

Reference 6)

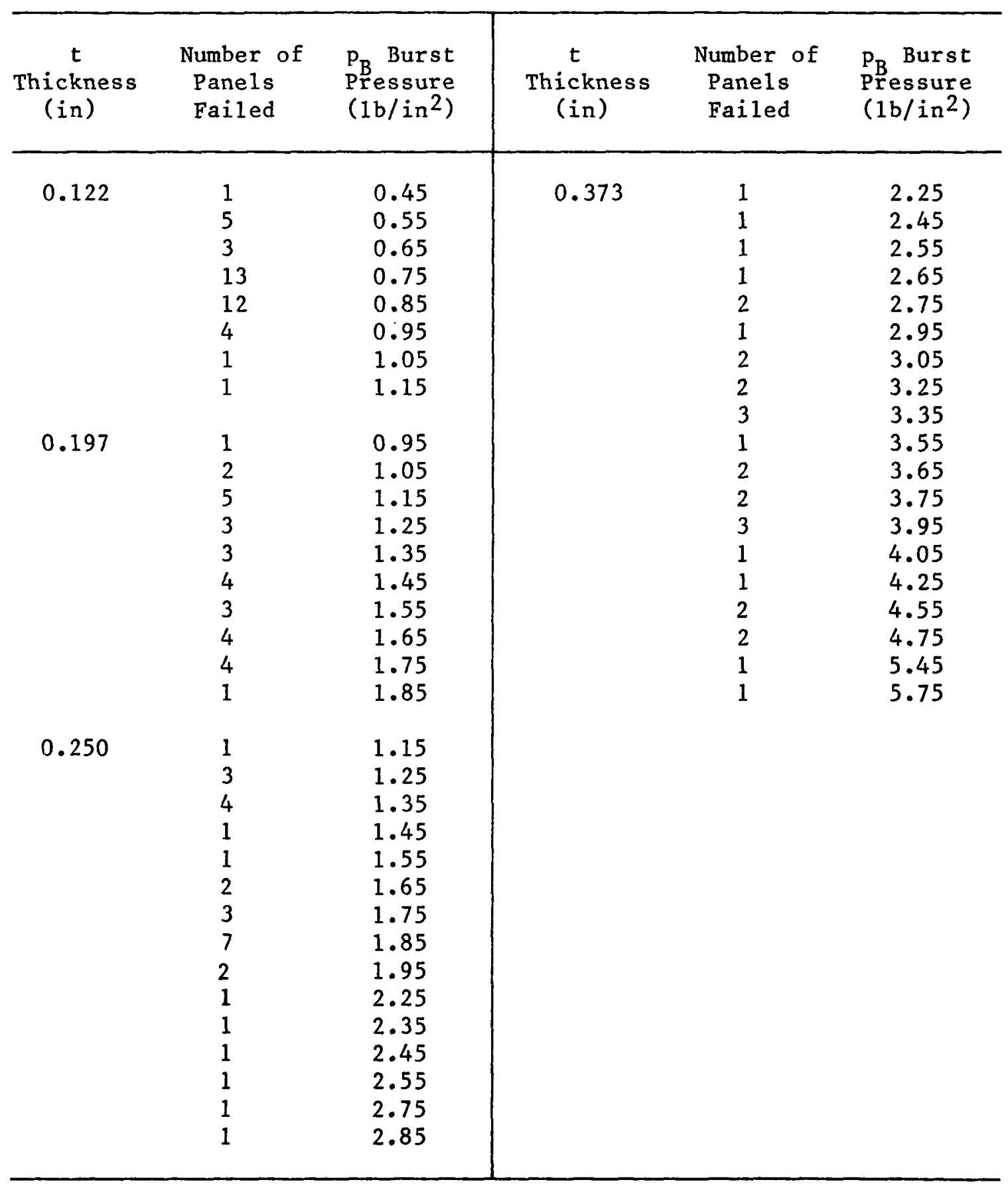


Table 2. Data for New Annealed Sheet Glass

Burst pressure data for 41-inch square, simply supported, new annealed sheet glass plates (from Bowles and Sugarman Reference 6)

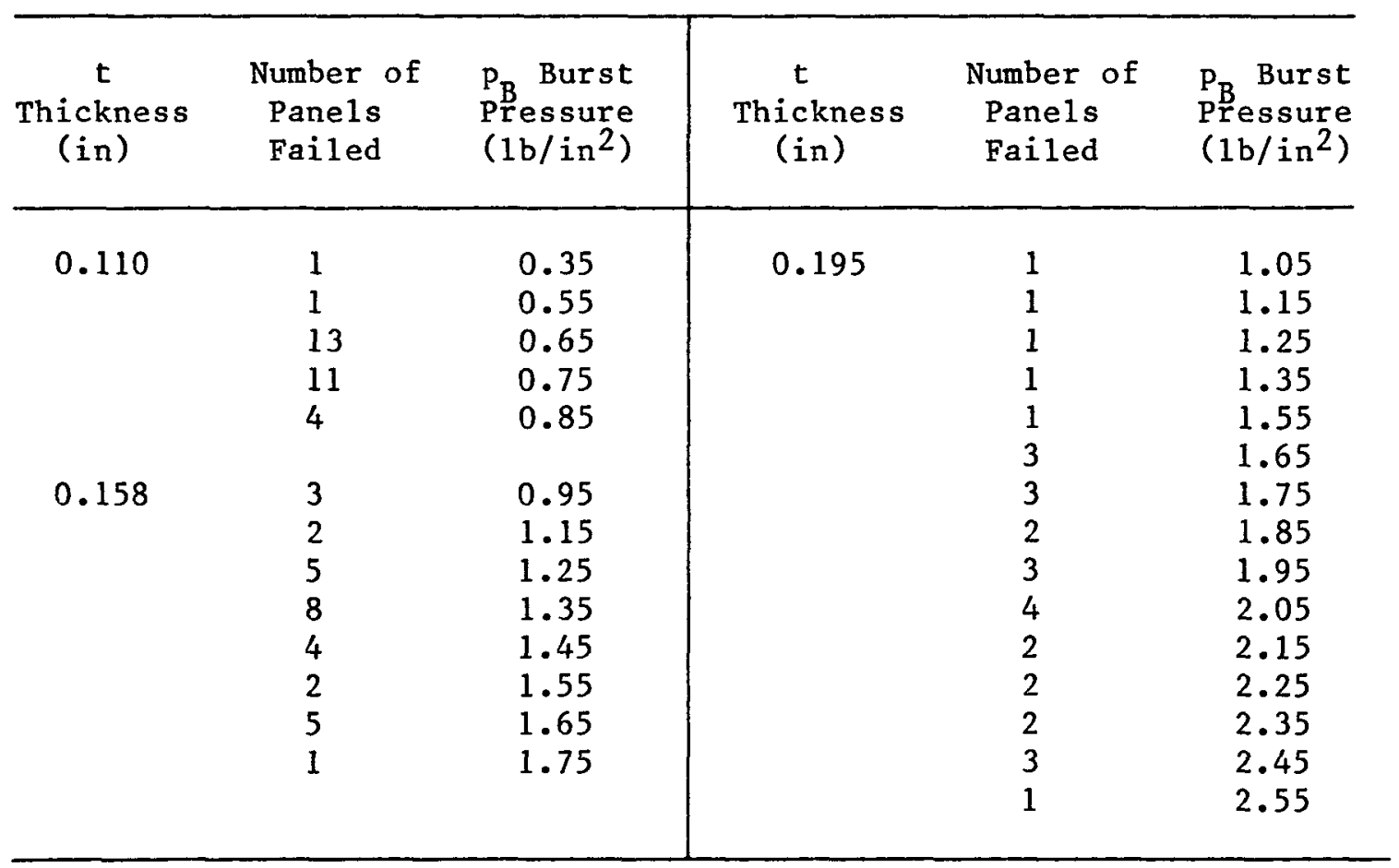


Table 3. Data for Weathered Annealed Sheet Glass (weathered side in tension)

Pressure-time history data for $0.219 \times 28.5 \times 60.5$-inch simply supported, 20-year-old weathered annealed sheet glass plates removed from Great Plains Life Building, Lubbock, Texas (from Beason - Reference 5).

\begin{tabular}{|c|c|c|c|c|c|}
\hline $\begin{array}{l}\text { Sample } \\
\text { No. }\end{array}$ & $\begin{array}{l}\tau \\
\text { Time } \\
(\mathrm{sec})\end{array}$ & $\begin{array}{c}\text { P } \\
\text { Pressure } \\
\left(1 b / \text { in }^{2}\right)\end{array}$ & $\begin{array}{c}\text { Sample } \\
\text { No. }\end{array}$ & $\begin{array}{l}\text { T } \\
\text { Time } \\
(\sec )\end{array}$ & $\begin{array}{c}\text { P } \\
\text { Pressure } \\
\left(1 \mathrm{~b} / \mathrm{in}^{2}\right)\end{array}$ \\
\hline 6 & $\begin{array}{r}5.0 \\
10.0 \\
15.0 \\
20.0 \\
25.0 \\
30.0 \\
33.5\end{array}$ & $\begin{array}{l}0.090 \\
0.206 \\
0.344 \\
0.449 \\
0.548 \\
0.626 \\
0.664\end{array}$ & 16 & $\begin{array}{r}5.0 \\
10.0 \\
15.0 \\
20.0 \\
25.0 \\
30.0 \\
30.0\end{array}$ & $\begin{array}{l}0.117 \\
0.277 \\
0.462 \\
0.560 \\
0.638 \\
0.730 \\
0.736\end{array}$ \\
\hline 8 & $\begin{array}{r}5.0 \\
10.0 \\
15.0 \\
20.0 \\
25.0 \\
30.0 \\
35.0 \\
40.0 \\
42.0\end{array}$ & $\begin{array}{l}0.141 \\
0.256 \\
0.364 \\
0.475 \\
0.568 \\
0.641 \\
0.710 \\
0.760 \\
0.765\end{array}$ & 18 & $\begin{array}{r}5.0 \\
10.0 \\
15.0 \\
20.0 \\
25.0 \\
30.0 \\
35.0 \\
40.0 \\
42.5\end{array}$ & $\begin{array}{l}0.125 \\
0.246 \\
0.349 \\
0.421 \\
0.508 \\
0.577 \\
0.644 \\
0.693 \\
0.725\end{array}$ \\
\hline 10 & $\begin{array}{l}5.0 \\
10.0 \\
15.0 \\
20.0 \\
25.0 \\
30.0 \\
35.0 \\
40.0 \\
45.0 \\
50.0 \\
55.0 \\
56.7\end{array}$ & $\begin{array}{l}0.112 \\
0.225 \\
0.335 \\
0.430 \\
0.515 \\
0.602 \\
0.691 \\
0.771 \\
0.867 \\
0.939 \\
0.986 \\
0.999\end{array}$ & 20 & $\begin{array}{r}5.0 \\
10.0 \\
15.0 \\
20.0 \\
25.0 \\
30.0 \\
35.0 \\
40.0 \\
45.0 \\
49.2 \\
5.0\end{array}$ & $\begin{array}{l}0.106 \\
0.228 \\
0.368 \\
0.475 \\
0.561 \\
0.612 \\
0.671 \\
0.711 \\
0.743 \\
0.759 \\
0.093\end{array}$ \\
\hline 12 & $\begin{array}{r}5.0 \\
10.0 \\
15.0 \\
20.0 \\
25.0\end{array}$ & $\begin{array}{l}0.090 \\
0.191 \\
0.304 \\
0.420 \\
0.520\end{array}$ & & $\begin{array}{l}10.0 \\
15.0 \\
20.0 \\
25.0 \\
29.5\end{array}$ & $\begin{array}{l}0.220 \\
0.330 \\
0.455 \\
0.575 \\
0.658\end{array}$ \\
\hline & $\begin{array}{l}30.0 \\
35.0 \\
40.0 \\
41.5\end{array}$ & $\begin{array}{l}0.600 \\
0.680 \\
0.737 \\
0.742\end{array}$ & 24 & $\begin{array}{r}5.0 \\
10.0 \\
15.0 \\
20.0 \\
23.0\end{array}$ & $\begin{array}{l}0.408 \\
0.617 \\
0.765 \\
0.860 \\
0.891\end{array}$ \\
\hline 14 & $\begin{array}{r}5.0 \\
10.0 \\
15.0 \\
20.0 \\
25.0 \\
30.0 \\
35.0 \\
40.0 \\
45.0 \\
50.0\end{array}$ & $\begin{array}{l}0.093 \\
0.179 \\
0.269 \\
0.377 \\
0.456 \\
0.518 \\
0.579 \\
0.609 \\
0.653 \\
0.668\end{array}$ & & & \\
\hline
\end{tabular}


Table 4. Data for Weathered Annealed Sheet Glass

(weathered side in tension)

Pressure-time history data for $0.219 \times 28.5 \times 28.5-i n c h$ simply supported, 20-year-old weathered annealed sheet glass plates removed from Great Plains Life Building, Lubbock, Texas (from Beason - Reference 5).

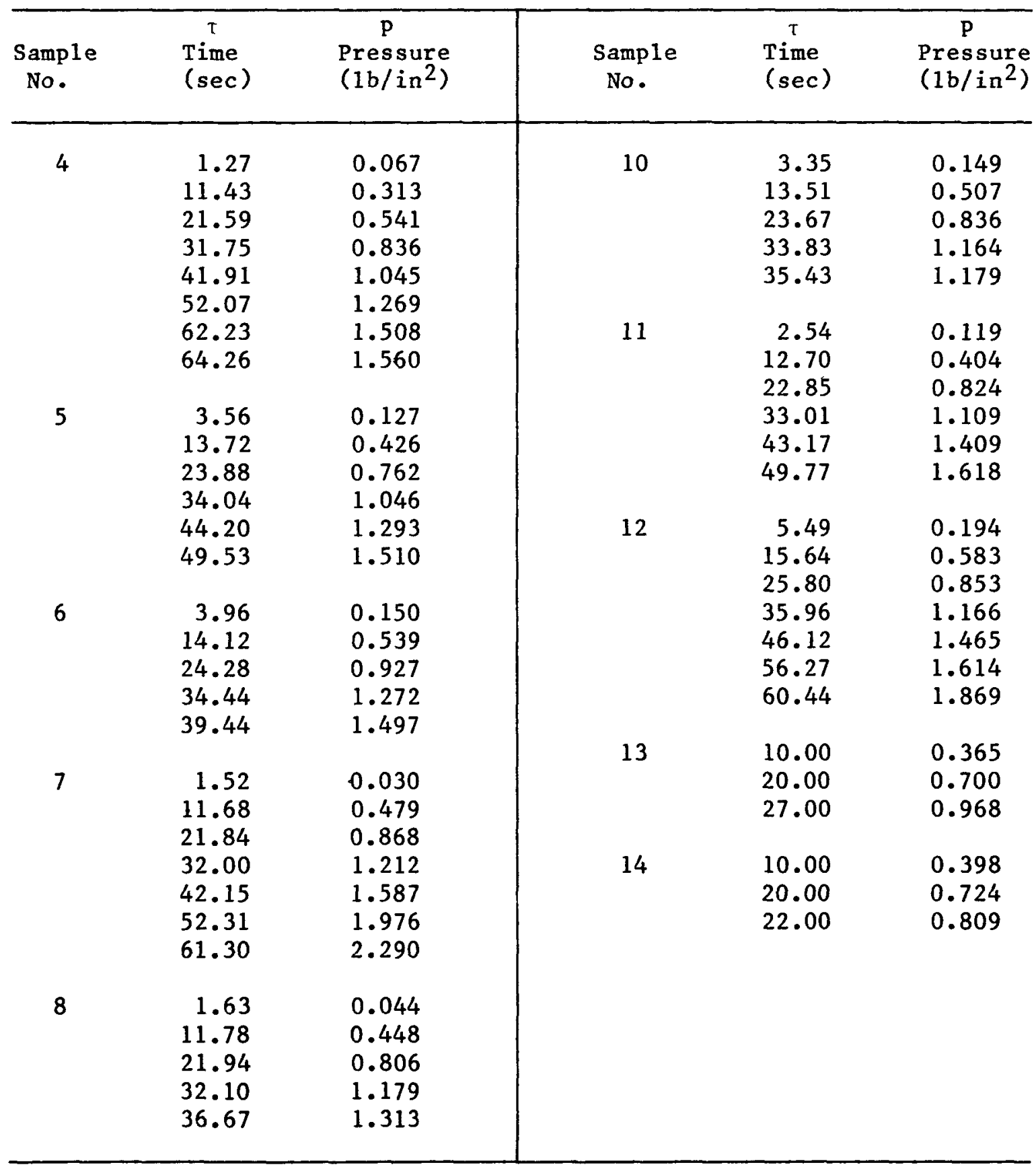


Table 5. Data for Weathered Annealed Sheet Glass (indoor side in tension)

Pressure-time history data for $0.219 \times 28.5 \times 60.5$-inch simply supported, 20-year-old weathered annealed sheet glass plates removed from Great Plains Life Building, Lubbock, Texas (from Beason - Reference 5).

\begin{tabular}{|c|c|c|c|c|c|}
\hline $\begin{array}{c}\text { Sample } \\
\text { No. }\end{array}$ & $\begin{array}{c}\tau \\
\text { Time } \\
(\sec )\end{array}$ & $\begin{array}{c}\text { P } \\
\text { Pressure } \\
\left(1 \mathrm{~b} / \text { in }^{2}\right)\end{array}$ & $\begin{array}{l}\text { Sample } \\
\text { No. }\end{array}$ & $\begin{array}{l}{ }^{\top} \\
\text { Time } \\
(\mathrm{sec})\end{array}$ & $\begin{array}{c}\text { P } \\
\text { Pressure } \\
\left(1 \mathrm{~b} / \text { in }^{2}\right)\end{array}$ \\
\hline 5 & $\begin{array}{r}3.0 \\
8.0 \\
13.0 \\
18.0 \\
23.0 \\
28.2\end{array}$ & $\begin{array}{l}0.004 \\
0.122 \\
0.269 \\
0.379 \\
0.446 \\
0.535\end{array}$ & 15 & $\begin{array}{r}5.0 \\
10.0 \\
15.0 \\
20.0 \\
21.2\end{array}$ & $\begin{array}{l}0.095 \\
0.217 \\
0.318 \\
0.416 \\
0.449\end{array}$ \\
\hline 7 & $\begin{array}{r}5.0 \\
10.0 \\
15.0 \\
20.0\end{array}$ & $\begin{array}{l}0.077 \\
0.168 \\
0.267 \\
0.372\end{array}$ & 17 & $\begin{array}{r}5.0 \\
10.0 \\
15.0 \\
18.0\end{array}$ & $\begin{array}{l}0.104 \\
0.273 \\
0.434 \\
0.530\end{array}$ \\
\hline & 24.7 & 0.462 & 19 & $\begin{array}{r}5.0 \\
10.0\end{array}$ & $\begin{array}{l}0.086 \\
0.144\end{array}$ \\
\hline 9 & $\begin{array}{r}5.0 \\
10.0 \\
15.0 \\
20.0 \\
25.0 \\
30.0 \\
35.0 \\
40.0\end{array}$ & $\begin{array}{l}0.097 \\
0.207 \\
0.29 .5 \\
0.368 \\
0.451 \\
0.542 \\
0.630 \\
0.721\end{array}$ & & $\begin{array}{l}15.0 \\
20.0 \\
25.0 \\
30.0 \\
35.0 \\
40.0 \\
44.7\end{array}$ & $\begin{array}{l}0.250 \\
0.339 \\
0.425 \\
0.502 \\
0.550 \\
0.587 \\
0.611\end{array}$ \\
\hline & $\begin{array}{l}45.0 \\
50.0 \\
51.2\end{array}$ & $\begin{array}{l}0.807 \\
0.888 \\
0.901\end{array}$ & 21 & $\begin{array}{r}5.0 \\
10.0 \\
15.0 \\
20.0\end{array}$ & $\begin{array}{l}0.104 \\
0.225 \\
0.374 \\
0.503\end{array}$ \\
\hline 11 & $\begin{array}{r}5.0 \\
10.0 \\
15.0\end{array}$ & $\begin{array}{l}0.069 \\
0.153 \\
0.222\end{array}$ & & $\begin{array}{l}25.0 \\
28.8\end{array}$ & $\begin{array}{l}0.604 \\
0.670\end{array}$ \\
\hline & $\begin{array}{l}20.0 \\
23.0 \\
25.0 \\
30.0 \\
35.0 \\
36.2\end{array}$ & $\begin{array}{l}0.267 \\
0.290 \\
0.346 \\
0.442 \\
0.514 \\
0.532\end{array}$ & 23 & $\begin{array}{r}5.0 \\
10.0 \\
15.0 \\
20.0 \\
25.0 \\
30.0 \\
34.5\end{array}$ & $\begin{array}{l}0.102 \\
0.221 \\
0.314 \\
0.404 \\
0.457 \\
0.492 \\
0.516\end{array}$ \\
\hline 13 & $\begin{array}{r}5.0 \\
10.0 \\
15.0 \\
20.0 \\
25.0 \\
30.0 \\
35.0 \\
40.0 \\
42.5\end{array}$ & $\begin{array}{l}0.127 \\
0.255 \\
0.350 \\
0.423 \\
0.482 \\
0.516 \\
0.547 \\
0.556 \\
0.562\end{array}$ & & & \\
\hline
\end{tabular}


Table 6. Data for Weathered Annealed Sheet Glass (indoor side in tension)

Pressure-time history data for $0.219 \times 28.5 \times 28.5$-inch simply supported, 20-year-old weathered annealed sheet glass plates removed from Great Plains Life Building, Lubbock, Texas (from Beason - Reference 5).

\begin{tabular}{|c|c|c|c|c|c|}
\hline $\begin{array}{l}\text { Sample } \\
\text { No. }\end{array}$ & $\begin{array}{c}\tau \\
\text { Time } \\
(\mathrm{sec})\end{array}$ & $\begin{array}{c}\text { p } \\
\text { Pressure } \\
\left(1 \mathrm{~b} / \mathrm{in}^{2}\right)\end{array}$ & $\begin{array}{c}\text { Sample } \\
\text { No. }\end{array}$ & $\begin{array}{c}\tau \\
\text { Time } \\
(\mathrm{sec})\end{array}$ & $\begin{array}{c}\text { p } \\
\text { Pressure } \\
\left(1 \mathrm{~b} / \text { in }^{2}\right)\end{array}$ \\
\hline 18 & $\begin{array}{r}9.50 \\
19.50 \\
29.50 \\
39.50\end{array}$ & $\begin{array}{l}0.330 \\
0.716 \\
1.046 \\
1.401\end{array}$ & 23 & $\begin{array}{r}3.30 \\
13.46 \\
23.62 \\
27.08\end{array}$ & $\begin{array}{l}0.137 \\
0.455 \\
0.849 \\
0.955\end{array}$ \\
\hline 19 & $\begin{array}{r}4.25 \\
14.25 \\
24.25 \\
34.25\end{array}$ & $\begin{array}{l}0.156 \\
0.484 \\
0.835 \\
0.124\end{array}$ & 24 & $\begin{array}{r}5.08 \\
15.28 \\
25.40 \\
35.56 \\
37.59\end{array}$ & $\begin{array}{l}0.273 \\
0.636 \\
0.985 \\
1.288 \\
1.363\end{array}$ \\
\hline 20 & $\begin{array}{r}6.5 \\
16.5 \\
26.5 \\
36.5 \\
46.5\end{array}$ & $\begin{array}{l}0.258 \\
0.571 \\
0.939 \\
1.229 \\
1.621\end{array}$ & 25 & $\begin{array}{l}10.16 \\
20.32 \\
30.48 \\
35.05\end{array}$ & $\begin{array}{l}0.332 \\
0.740 \\
1.149 \\
1.300\end{array}$ \\
\hline 21 & $\begin{array}{r}4.06 \\
14.22 \\
24.38 \\
34.54 \\
42.21\end{array}$ & $\begin{array}{l}0.166 \\
0.529 \\
0.878 \\
1.197 \\
1.438\end{array}$ & 26 & $\begin{array}{r}3.64 \\
13.80 \\
23.96 \\
25.59\end{array}$ & $\begin{array}{l}0.166 \\
0.513 \\
0.906 \\
0.997\end{array}$ \\
\hline 22 & $\begin{array}{r}4.32 \\
14.48 \\
24.64 \\
34.08 \\
37.74\end{array}$ & $\begin{array}{l}0.196 \\
0.604 \\
0.920 \\
1.176 \\
1.313\end{array}$ & 27 & $\begin{array}{r}1.78 \\
11.94 \\
22.10 \\
32.26 \\
42.42 \\
43.94\end{array}$ & $\begin{array}{l}0.135 \\
0.453 \\
0.816 \\
1.073 \\
1.632 \\
1.647\end{array}$ \\
\hline
\end{tabular}


Table 7. Data for New Tempered Float Glass

Pressure-time history data for $0.125 \times 48 \times 48$-inch simply supported, new tempered float glass plates (from Wilson -Reference 7).

\begin{tabular}{|c|c|c|c|c|c|}
\hline $\begin{array}{c}\text { Sample } \\
\text { No. }\end{array}$ & $\begin{array}{c}\tau \\
\text { Time } \\
(\sec )\end{array}$ & $\begin{array}{c}\text { p } \\
\text { Pressure } \\
\left(1 \mathrm{~b} / \mathrm{in}^{2}\right)\end{array}$ & $\begin{array}{c}\text { Sample } \\
\text { No. }\end{array}$ & $\begin{array}{c}\tau \\
\text { Time } \\
(\mathrm{sec})\end{array}$ & $\begin{array}{c}\text { p } \\
\text { Pressure } \\
\left(1 b / \text { in }^{2}\right)\end{array}$ \\
\hline 1 & $\begin{array}{l}10 \\
20 \\
30 \\
40 \\
50 \\
60 \\
70 \\
80\end{array}$ & $\begin{array}{l}0.27 \\
0.65 \\
1.02 \\
1.30 \\
1.50 \\
1.61 \\
1.65 \\
1.69\end{array}$ & 7 & $\begin{array}{l}10 \\
20 \\
30 \\
40 \\
50 \\
60 \\
70 \\
80 \\
90\end{array}$ & $\begin{array}{l}0.23 \\
0.45 \\
0.63 \\
0.69 \\
0.71 \\
0.77 \\
1.05 \\
1.79 \\
1.95\end{array}$ \\
\hline 4 & $\begin{array}{l}10 \\
20 \\
30 \\
40 \\
50 \\
60 \\
70 \\
80 \\
90\end{array}$ & $\begin{array}{l}0.17 \\
0.47 \\
0.67 \\
0.99 \\
1.25 \\
1.45 \\
1.59 \\
1.69 \\
1.75\end{array}$ & 8 & $\begin{array}{l}10 \\
20 \\
30 \\
40 \\
50 \\
60 \\
70 \\
80 \\
90\end{array}$ & $\begin{array}{l}0.30 \\
0.49 \\
0.63 \\
0.66 \\
0.69 \\
0.71 \\
0.73 \\
0.75 \\
0.95\end{array}$ \\
\hline 5 & $\begin{array}{l}10 \\
20 \\
30 \\
40 \\
50 \\
60\end{array}$ & $\begin{array}{l}0.19 \\
0.45 \\
0.57 \\
0.65 \\
0.67 \\
0.71\end{array}$ & & $\begin{array}{l}100 \\
110 \\
120 \\
130 \\
140\end{array}$ & $\begin{array}{l}1.23 \\
1.43 \\
1.61 \\
1.75 \\
1.90\end{array}$ \\
\hline & $\begin{array}{r}70 \\
80 \\
90 \\
100 \\
110\end{array}$ & $\begin{array}{l}0.87 \\
1.17 \\
1.37 \\
1.51 \\
1.59\end{array}$ & 9 & $\begin{array}{l}10 \\
20 \\
30 \\
40 \\
50 \\
60\end{array}$ & $\begin{array}{l}0.22 \\
0.40 \\
0.54 \\
0.64 \\
0.67 \\
0.68\end{array}$ \\
\hline 6 & $\begin{array}{r}10 \\
20 \\
30 \\
40 \\
50 \\
60 \\
70 \\
80 \\
90 \\
100 \\
110 \\
120\end{array}$ & $\begin{array}{l}0.21 \\
0.39 \\
0.55 \\
0.65 \\
0.67 \\
0.69 \\
0.87 \\
1.19 \\
1.37 \\
1.51 \\
1.61 \\
1.69\end{array}$ & 10 & $\begin{array}{r}70 \\
80 \\
90 \\
100 \\
110 \\
120 \\
130 \\
\\
10 \\
20 \\
30 \\
40 \\
50 \\
60 \\
70 \\
80 \\
90 \\
100 \\
110\end{array}$ & $\begin{array}{l}0.72 \\
0.77 \\
0.90 \\
1.00 \\
1.10 \\
1.17 \\
1.80 \\
\\
0.25 \\
0.46 \\
0.58 \\
0.65 \\
0.69 \\
0.72 \\
0.91 \\
1.20 \\
1.41 \\
1.55 \\
1.65\end{array}$ \\
\hline
\end{tabular}


The data in Tables 1 through 7 are normalized to a breaking stress corresponding to a constant stress applied to a plate of 1 square meter surface area for 1 minute. This normalization is accomplished as follows:

(a) First, the pressure-time histories for the various tests are converted to stress-time histories, using Figure 7 and Equations 2 and 3 . This is necessary since the stress-time history is needed and the stress-pressure relationship is nonlinear.

(b) An analytical expression of the form $\sigma=k \tau^{\beta}$ is fitted to the above stress-time data.

(c) This stress-time relationship together with Equation 4 (repeated here)

$$
\int_{0}^{\tau_{B}}[\sigma(\tau)]^{\alpha} d \tau=\text { constant }
$$

is used to determine $\sigma_{1}$, that constant stress which will cause the panel to break after 1-minute load duration. For a glass load-bearing plate which fails at time $\tau_{B}$ and stress $\sigma_{B}$, to which the stress is applied gradually according to the relationship $\sigma=k \tau^{\beta}$, and bearing in mind that we want to develop a relationship to normalize the data to the 1 -minute breaking stress, $\sigma_{1}$, where $\tau$ is in seconds and $\tau_{B}=60$ seconds, we substitute in Equation 4

$\int_{0}^{60}\left(\sigma_{1}\right)^{\alpha} d \tau=\int_{0}^{\tau_{B}}\left(k \tau^{\beta}\right)^{\alpha} d \tau$

Simplifying, we obtain

$\sigma_{1}=\frac{k \tau_{\beta} \beta+\frac{1}{\alpha}}{[60(\alpha \beta+1)]^{1 / \alpha}}$

where

$\sigma_{1}=$ constant stress that will cause the panel to break at 1-minute load duration

$k, \beta=$ empirical constants obtained by fitting an analytical expression to the stress-time data of step b above.

$\alpha=$ empirical constant associated with the decrease of glass breakage stress with increased load duration. From Figure 9 we note that values of $\alpha$ equal to 12 for annealed glass and to 40 for tempered glass fit the data for load durations in the 5-second to 5-minute range. 
$\tau_{B}=\quad$ time in seconds at which a given glass panel
fails.

(d) Note that the l-minute breaking stress obtained for each plate tested applies only to plates having the same surface area as the test plate. Employing Equation 6, the one minute breaking strengths are further normalized to the 1-minute breaking strength corresponding to a glass plate with a surface area of 1 square meter, as follows:

$$
\sigma_{11}=(\mathrm{A})^{1 / 6} \sigma_{1}
$$

where

$$
\begin{aligned}
& \sigma_{11=} \begin{array}{l}
\text { constantly applied stress that will cause a pane1 } \\
\text { of 1-square-meter surface area to break at } \\
1 \text {-minute load duration. }
\end{array} \\
& \mathrm{A}=\quad \begin{array}{l}
\text { surface area of the test plate expressed in } \\
\text { square meters. }
\end{array} \\
& \sigma_{1=} \begin{array}{l}
\text { constant } 1 y \text { applied stress that will cause the } \\
\text { test panel of A square meters to break at } 1 \\
\text { minute load duration. }
\end{array}
\end{aligned}
$$

The normalized breaking strengths given in Tables 8 through 14 are produced following the procedure outlined above.

\section{Breaking Strength versus Probability of Failure}

Weibull statistical analysis techniques are applied to the breakage stress data of Tables 8 through 14 to obtain analytical expressions for the probability of failure as a function of the breakage stress. The use of the Weibull distribution represents state-of-the-art statistical analysis of the fracture of brittle materials. The Weibull distribution generally provides a better fit to experimental fracture data than does the Gaussian distribution, especially at low probabilities of failure. 
Table 8. Normalized Breakage Stress for New Annealed Plate Glass

Bowles and Sugarman's burst pressure data for 41-inch square, simply supported, new annealed plate glass plates (Table 1) normalized to $\sigma_{11}$, that constantly applied stress that will cause a plate of 1-square-meter surface area to fail at 1-minute load duration.

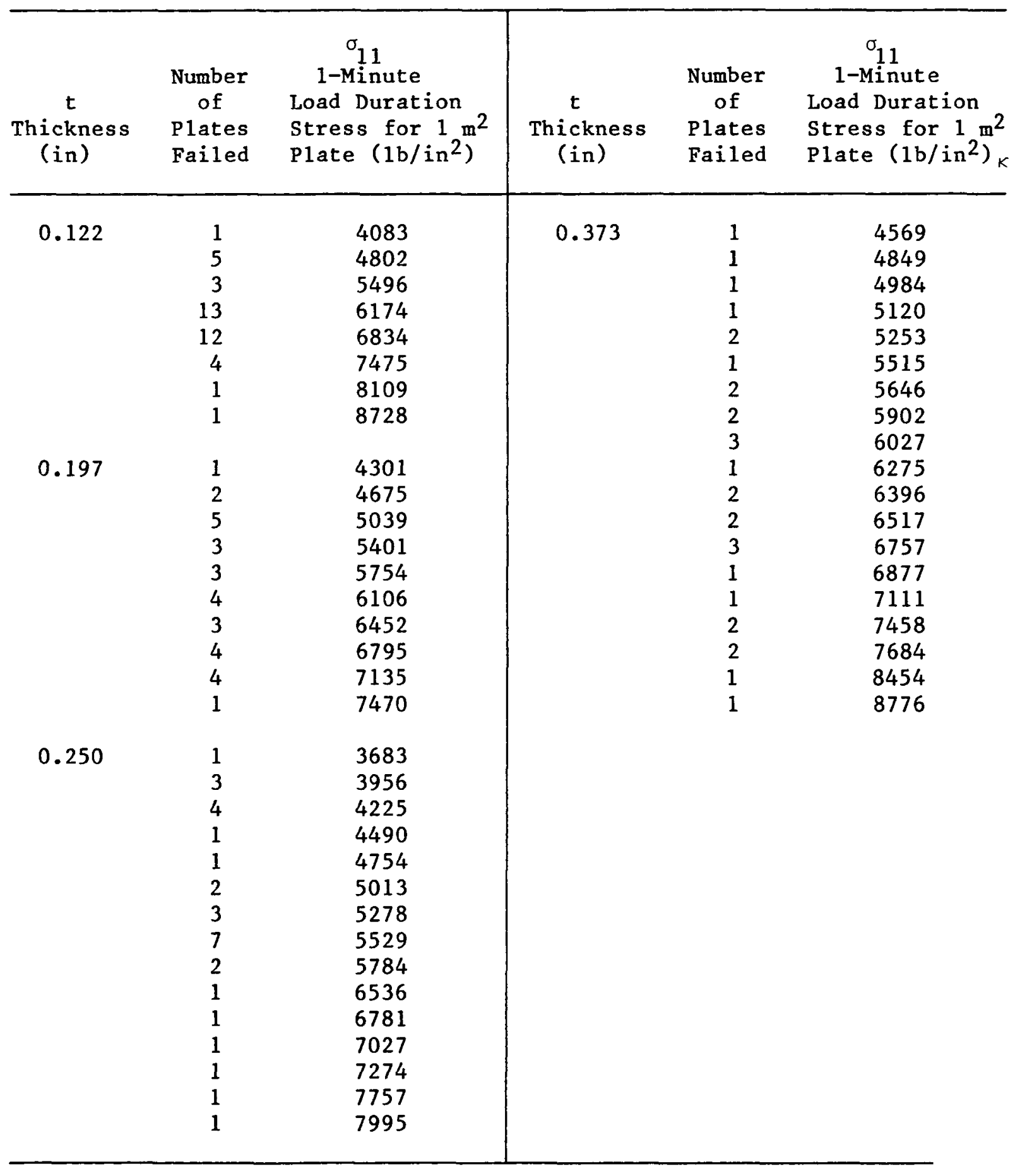


Table 9. Normalized Breakage Stress for New Annealed Sheet Glass

Bowles and Sugarman's burst pressure data for 41-inch square, simply supported, new annealed sheet glass plates (Table 2) normalized to $\sigma_{11}$, that constantly applied stress that will cause a plate of 1-square-meter surface area to fail at 1-minute load duration.

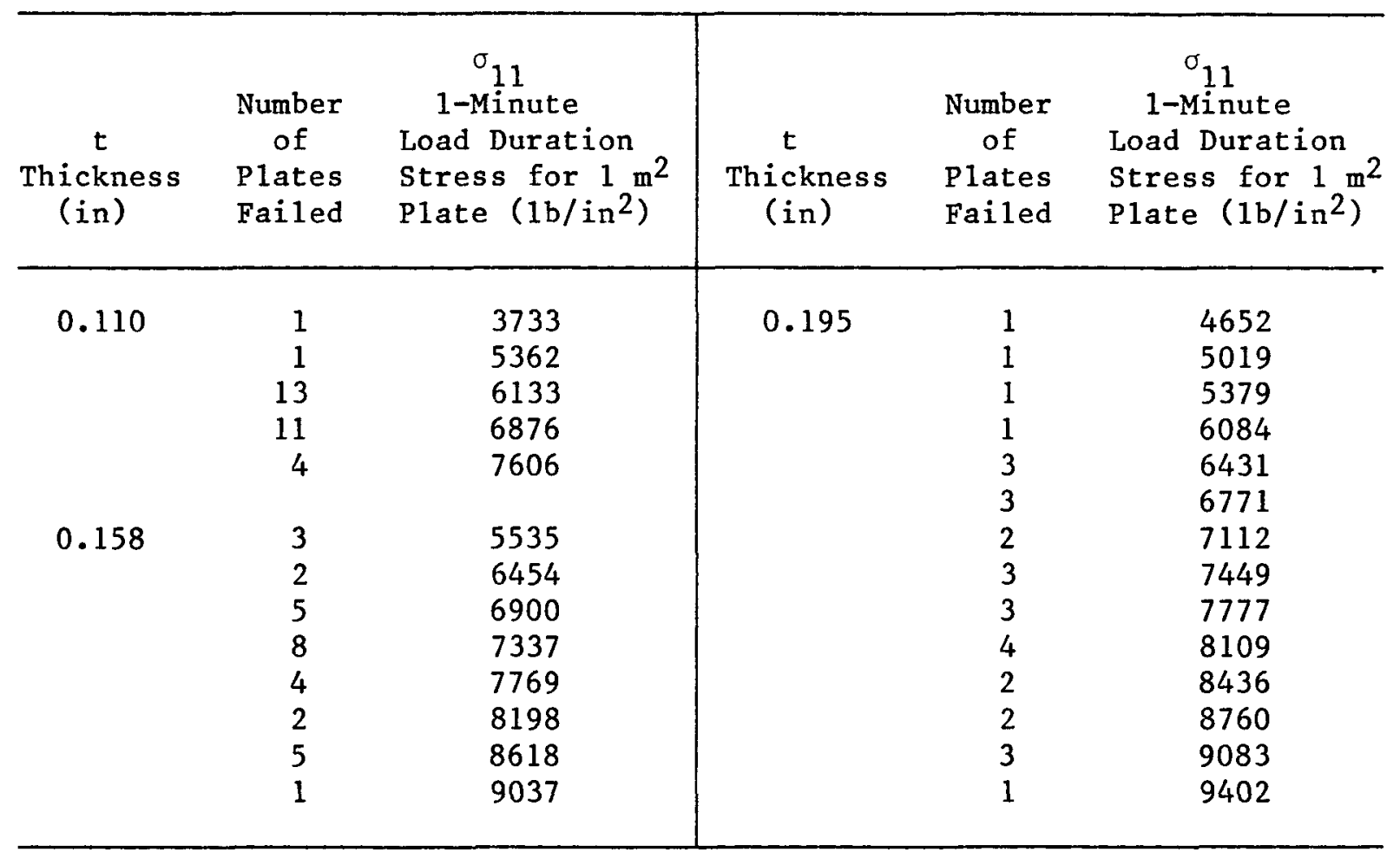


Table 10. Normalized Breakage Stress for

Weathered Annealed Sheet Glass

(weathered side in tension)

Beason's burst pressure data for $0.219 \times 28.5 \times 60.5-i n c h$, simply supported, 20-year-old weathered annealed sheet glass removed from Great Plains Life Building, Lubbock, Texas (Table 3) normalized to $\sigma_{11}$, that constantly applied stress that will cause a plate of 1-square-meter surface area to fail at 1-minute load duration.

\begin{tabular}{ccc}
\hline $\begin{array}{c}t \\
\text { Thickness } \\
\text { in) }\end{array}$ & $\begin{array}{c}\text { Number of } \\
\text { Plates Failed }\end{array}$ & $\begin{array}{c}\sigma_{11} \\
\text { 1-Minute Load Duration Stress } \\
\left.\text { for } 1 \mathrm{~m}^{2} \text { P1ate (1b/in }\right)^{2}\end{array}$ \\
\hline 0.219 & 1 & 4438 \\
& 1 & 4562 \\
1 & 4934 \\
1 & 5052 \\
1 & 5079 \\
1 & 5285 \\
1 & 5370 \\
1 & 5421 \\
1 & 5700 \\
1 & 6524 \\
\hline
\end{tabular}

Table 11. Normalized Breakage Stress for Weathered Annealed Sheet Glass (weathered side in tension)

Beason's burst pressure data for $0.219 \times 28.5 \times 28.5$-inch, simply supported, 20-year-old weathered annealed sheet glass removed from Great Plains Life Building, Lubbock, Texas (Table 4) normalized to $\sigma_{11}$, that constantly applied stress that will cause a plate of 1-square-meter surface area to fail at 1-minute load duration.

\begin{tabular}{|c|c|c|}
\hline $\begin{array}{l}t \\
\text { Thickness } \\
\text { (in) }\end{array}$ & $\begin{array}{c}\text { Number of } \\
\text { Plates Failed }\end{array}$ & $\begin{array}{l}\sigma_{11} \\
\text { 1-Minute Load Duration Stress } \\
\text { for } 1 \mathrm{~m}^{2} \text { Plate }\left(1 \mathrm{~b} / \mathrm{in}^{2}\right)\end{array}$ \\
\hline 0.219 & $\begin{array}{l}1 \\
1 \\
1 \\
1 \\
1 \\
1 \\
1 \\
1 \\
1 \\
1 \\
\end{array}$ & $\begin{array}{l}2309 \\
2690 \\
3306 \\
3471 \\
3801 \\
3894 \\
4094 \\
4127 \\
4573 \\
5188 \\
\end{array}$ \\
\hline
\end{tabular}


Table 12. Normalized Breakage Stress for Weathered Annealed Sheet Glass (indoor side in tension)

Beason's burst pressure data for $0.219 \times 28.5 \times 60.5-i n c h$, simply supported, 20-year-old weathered annealed sheet glass removed from Great Plains Life Building, Lubbock, Texas (Table 5) normalized to $\sigma_{11}$, that constantly applied stress that will cause a plate of 1-square-meter surface area to fail at 1-minute load duration.

\begin{tabular}{ccc}
$\begin{array}{c}t \\
\text { Thickness } \\
(\text { in })\end{array}$ & $\begin{array}{c}\text { Number of } \\
\text { Plates Failed }\end{array}$ & $\begin{array}{c}\sigma_{11} \\
\text { 1-Minute Load Duration Stress } \\
\left.\text { for } 1 \mathrm{~m}^{2} \text { Plate (1b/in }{ }^{2}\right)\end{array}$ \\
\hline \multirow{2}{*}{0.219} & 1 & 3200 \\
& 1 & 3312 \\
1 & 3579 \\
1 & 3802 \\
1 & 3815 \\
1 & 3926 \\
1 & 4367 \\
1 & 4510 \\
1 & 4523 \\
1 & 5804 \\
\hline
\end{tabular}

Table 13. Normalized Breakage Stress for Weathered Annealed Sheet Glass (Indoor side in Tension)

Beason's burst pressure data for $0.219 \times 28.5 \times 28.5$-inch, simply supported, 20-year-old weathered annealed sheet glass removed from Great Plains Life Building, Lubbock, Texas (Table 6) normalized to $\sigma_{11}$, that constantly applied stress that will cause a plate of 1-square-meter surface area to fail at 1-minute load duration.

\begin{tabular}{ccc}
$\begin{array}{c}t \\
\begin{array}{c}\text { Thickness } \\
\text { in })\end{array}\end{array}$ & $\begin{array}{c}\text { Number of } \\
\text { Plates Failed }\end{array}$ & $\begin{array}{c}\sigma_{11} \\
\text { 1-Minute Load Duration Stress } \\
\left.\text { for } 1 \mathrm{~m}^{2} \text { Plate (1b/in }\right)\end{array}$ \\
\hline \multirow{2}{*}{0.219} & 1 & 2662 \\
& 1 & 2741 \\
1 & 3088 \\
1 & 3431 \\
1 & 3507 \\
1 & 3601 \\
1 & 3639 \\
1 & 3763 \\
1 & 3987 \\
\hline
\end{tabular}


Table 14. Normalized Breakage Stress for

New Tempered Float Glass

Wilson's burst pressure data for $0.125 \times 48 \times 48$-inch, simply supported, new tempered float glass (Table 7) normalized to $\sigma_{11}$, that constantly applied stress that will cause a plate of 1-square-meter surface area to fail at 1 -minute load duration.

\begin{tabular}{ccc}
\hline $\begin{array}{c}t \\
\text { Thickness } \\
\text { (in) }\end{array}$ & $\begin{array}{c}\text { Number of } \\
\text { Plates Failed }\end{array}$ & $\begin{array}{c}\sigma_{11} \\
\text { 1-Minute Load Duration Stress } \\
\left.\text { for } 1 \mathrm{~m}^{2} \text { Plate (1b/in }\right)\end{array}$ \\
\hline \multirow{2}{*}{0.125} & 1 & 16986 \\
1 & 1 & 17344 \\
1 & 17816 \\
1 & 17966 \\
1 & 18031 \\
1 & 18531 \\
1 & 19264 \\
\hline
\end{tabular}

The analytical expression for the Weibull distribution used here is

$$
P_{f}=1-e^{-\left(\frac{\sigma_{11}-\sigma_{u}}{\sigma_{0}}\right)^{m}}
$$

where

$$
\begin{aligned}
& P_{\mathrm{f}}=\text { probability of failure } \\
& \sigma_{11}=\text { breakage stress for 1-minute load duration for } \\
& \text { 1-square-meter plate } \\
& \sigma_{u}=\text { lower bound stress for which the probability of failure } \\
& \text { is zero. } \\
& \sigma_{0}=\text { characteristic stress } \\
& \text { m }=\text { Weibull modulus }
\end{aligned}
$$


The constants $\sigma_{\mathrm{u}}, \sigma_{\mathrm{o}}$ and $\mathrm{m}$ for a given data set are determined from a curve-fitting method described by Sines (Reference 17). The basic procedure is as follows:

(a) Take the logarithm of both sides of Equation 10 twice to produce the following relationship:

$\log \log \left(\frac{1}{1-P_{f}}\right)=m \log \left(\sigma_{11}-\sigma_{u}\right)-m \log \sigma_{o}-0.362216$

(b) For any given data set of Tables 8 through 14 assume a value of $\sigma_{u}$.

(c) Compute the experimental $P_{f}$ associated with each value of $\sigma_{11}$ :

$$
P_{E}=\frac{n}{N+1}
$$

where

$\mathrm{n}=$ cumulative number of failures at or below a given $\sigma_{11}$.

$\mathrm{N}=$ total number of samples in a given data set.

(d) Now plot $\log \log \left(\frac{1}{1-P_{f}}\right)$ versus $\log \left(\sigma_{11}-\sigma_{u}\right)$ and compute the best fit straight line through these points by the method of "least squares."

(e) Compute the correlation coefficient which measures how well the above best fit straight line fits the experimental data. The correlation coefficient will have a value between zero and one, with one indicating a perfect fit.

(f) Vary $\sigma_{u}$ until the correlation coefficient attains a maximum value (that is, closest to one); this is the value of $\sigma_{u}$ for the Weibull distribution which best fits the experimental data.

(g) The Weibull modulus, $m$, is the slope of the best fit straight line corresponding to the above value of $\sigma_{u}$.

(h) Having $\sigma_{u}$ and $m$, compute $\sigma_{o}$ from the relationship of step $(a)$. We now have all of the constants $\left(\sigma_{u}, \sigma_{o}, m\right)$ to form the Weibull distribution (Equation 10) which best describes a given data set. 
Robert Weaver of Jet Propulsion Laboratory wrote a FORTRAN computer program to automate the above procedure. A listing of this program together with a sample output is given in Appendix II. This analysis was performed on each of the 12 normalized data sets of Tables 8 through 14. Figure 11 shows the resulting "best fit" Weibull distributions (lines) together with the experimental $P_{f}, \sigma_{11}$ pairs (symbols).

In comparing the analytical Weibull distributions for the various annealed glass types (new plate, new sheet and weathered sheet), it is very interesting to note that the mean strength of the new annealed sheet glass samples is generally higher than that of the new annealed plate glass samples. Moreover, the lower bound strength $\left(P_{f}=0\right)$ of the new annealed plate glass samples has some appreciable value $\left(\sigma_{u}\right.$ greater than about $3200 \mathrm{1b} / \mathrm{in}^{2}$ ) while the lower bound strength of a11 new annealed sheet glass samples is zero. This can be explained by considering the probable nature of the flaws in the surface of these glass types resulting from the different manufacturing methods used to produce plate and sheet glass.

Sheet glass is produced by drawing the molten glass from a bath. The process is continuous and the glass cools as it is drawn over rollers. No subsequent operations are performed. The general surface condition of sheet glass might be described as "fire-polished", which results in the high mean strength noted for sheet glass. On the other hand, the chance for a large surface inclusion or flaw exists, which explains why the new annealed sheet glass samples have zero lower bound strength. The final operation in the manufacture of plate glass is grinding the surface smooth and flat. This results in a fairly even surface flaw size distribution, with the large inclusions and flaws having been removed. This accounts for the lower mean strength and the substantial lower bound strength of plate glass. The strong dependence of the measured mean strength and strength distribution on the surface condition of the glass has been noted by others. Brown (Reference 14) states: "Surface roughening results in reduced average strength and reduced variability, whereas smoothing operations result in increased strength with attendant increased variability."

It is interesting to note the different character of the Weibull distributions for the four lots of weathered annealed glass tested by Beason. Beason tested two lots of 12 plates each at the original size removed from the Great Plains Life Building in Lubbock, Texas; that is, $0.219 \times 28.5 \times 60.5$ inches. The additional two lots tested included 10 samples each of plates $0.219 \times 28.5 \times 28.5$ inches cut from the original plates. For both sizes, 10 plates were tested with the weathered side in tension and 10 plates with the indoor side in tension. The data from the plates tested with the indoor side in tension are included for comparative purposes and because they are generally supportive of the following conclusions: 


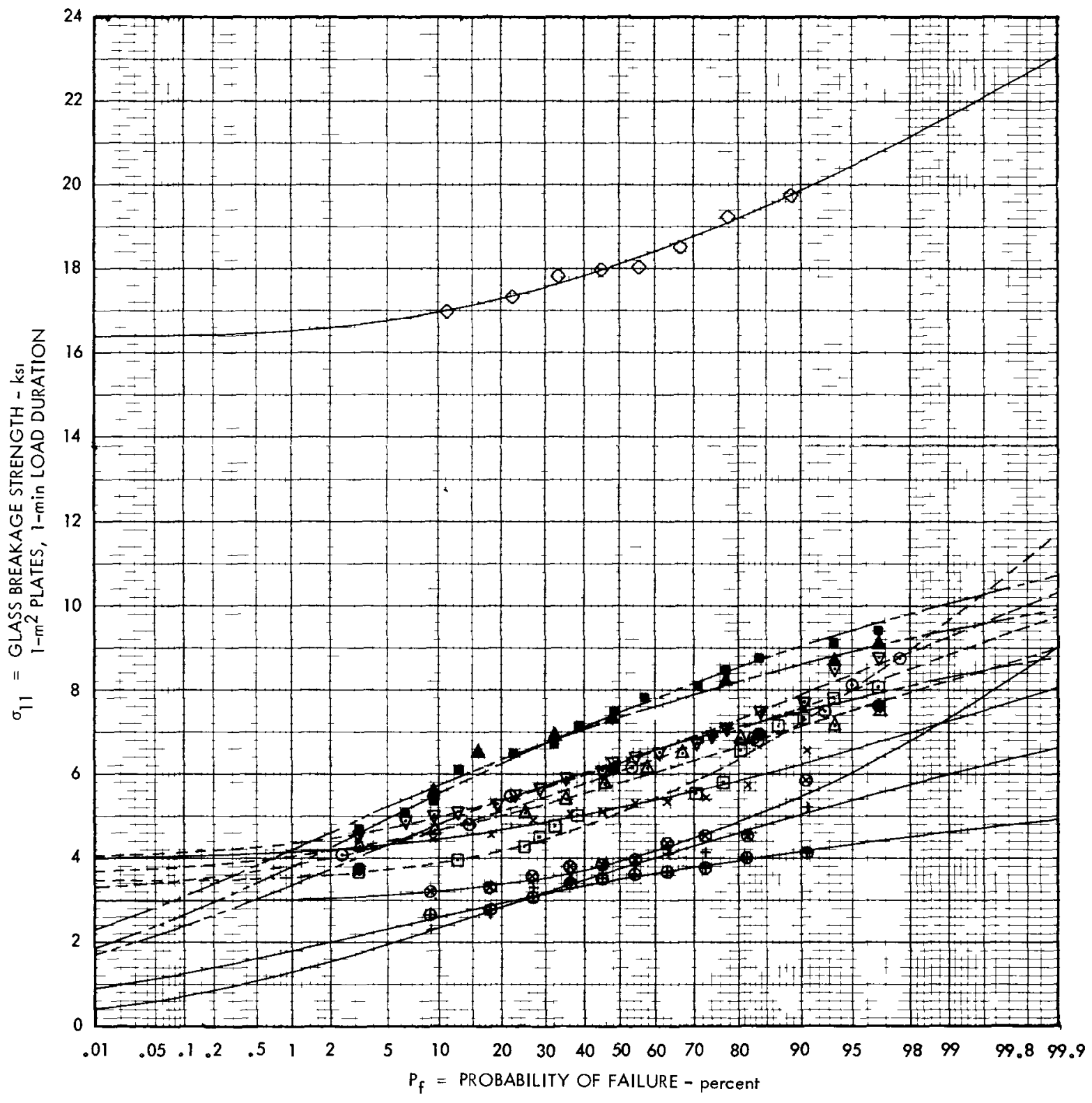

\begin{tabular}{|c|c|c|c|c|c|c|c|c|}
\hline \multirow[b]{2}{*}{$\begin{array}{l}\text { Glass } \\
\text { Type }\end{array}$} & \multirow[b]{2}{*}{ Investigator } & \multirow[b]{2}{*}{$\begin{array}{c}\text { Glass Plate Size } \\
\text { (Inches) }\end{array}$} & \multirow{2}{*}{$\begin{array}{l}\text { Normalized Data } \\
\text { (Tables 8-14) } \\
\qquad P_{f}=\frac{n}{N+1}\end{array}$} & \multicolumn{5}{|c|}{$\begin{array}{l}\text { Best Fit Weibull Curves } \\
\qquad \mathrm{P}_{\mathrm{f}}=1-\mathrm{e}^{-\left(\frac{\sigma_{11}-\sigma_{\mathrm{u}}}{\sigma_{\mathrm{o}}}\right)^{\mathrm{m}}}\end{array}$} \\
\hline & & & & Line & $o_{\dot{u}}$ & $\begin{array}{l}\sigma_{0} \\
\mathrm{ps}_{1}\end{array}$ & m & C.C.* \\
\hline $\begin{array}{l}\text { New } \\
\text { Annealed } \\
\text { Plate } \\
\text { Glass } \\
\end{array}$ & $\begin{array}{l}\text { Bowles and } \\
\text { Sugarman } \\
\text { (Ref. 6) }\end{array}$ & $\begin{array}{l}0.122 \times 41 \times 41 \\
0.197 \times 41 \times 41 \\
0.250 \times 41 \times 41 \\
0.373 \times 41 \times 41 \\
\end{array}$ & $\begin{array}{l}\bigcirc \\
\triangle \\
\square\end{array}$ & 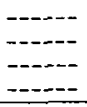 & $\begin{array}{l}3205 \\
3656 \\
3499 \\
4044 \\
\end{array}$ & $\begin{array}{l}3258 \\
2471 \\
2057 \\
2600 \\
\end{array}$ & $\begin{array}{l}2.8187 \\
2.5214 \\
1.3985 \\
2.1961 \\
\end{array}$ & $\begin{array}{l}.992 \\
.995 \\
.991 \\
.997 \\
\end{array}$ \\
\hline $\begin{array}{l}\text { New } \\
\text { Annealed } \\
\text { Sheet }\end{array}$ & $\begin{array}{l}\text { Bowles and } \\
\text { Sugarman } \\
\text { (Ref. 6) }\end{array}$ & $\begin{array}{l}0.110 \times 41 \times 41 \\
0.158 \times 41 \times 41 \\
0.195 \times 41 \times 41\end{array}$ & 8 & $\overline{-1}$ & $\begin{array}{l}0 \\
0 \\
0\end{array}$ & $\begin{array}{l}6617 \\
7673 \\
7892\end{array}$ & $\begin{array}{l}69049 \\
7.7111 \\
6.3892\end{array}$ & $\begin{array}{l}.936 \\
.986 \\
.996\end{array}$ \\
\hline $\begin{array}{l}\text { Glass } \\
\text { Weathered } \\
\text { Annealed } \\
\text { Glass }\end{array}$ & $\begin{array}{l}\text { Beason } \\
\text { (Ref. 5) }\end{array}$ & $\begin{array}{l}0.219 \times 285 \times 60.5 \\
0.219 \times 28.5 \times 28.5 \\
0.219 \times 285 \times 60.5 \\
0.219 \times 28.5 \times 28.5 \\
\end{array}$ & 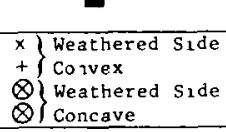 & $\bar{\square}$ & $\begin{array}{r}4039 \\
0 \\
3008 \\
0 \\
\end{array}$ & $\begin{array}{l}1393 \\
4121 \\
1250 \\
3679 \\
\end{array}$ & $\begin{array}{l}1.8402 \\
4.1036 \\
1.2370 \\
6.7021 \\
\end{array}$ & $\begin{array}{r}.980 \\
989 \\
.987 \\
.979 \\
\end{array}$ \\
\hline $\begin{array}{l}\text { Tempered } \\
\text { Float Glass }\end{array}$ & $\begin{array}{l}\text { Wilson } \\
(\operatorname{Ref} .7)\end{array}$ & $0125 \times 48 \times 48$ & 0 & - & 16395 & 2129 & 16887 & 991 \\
\hline
\end{tabular}

Figure 11. Breakage Strength versus Probability of Failure for Simply Supported, Glass Plates subjected to a Uniform Normal Pressure (Normalized to $1 \mathrm{~m}^{2}$ Surface Area and 1-Minute Load Duration) 
(a) Comparing the Weibull curves for the two different plate sizes tested with the indoor side in tension supports the use of the $1 / 6$ power areal correction factor.

(b) Since both sample lots of $28.5 \times 28.5$-inch plates have zero lower bound strength $\left(\sigma_{u}=0\right)$ whereas both sample lots of $28.5 \times 60.5$-inch plates have substantial lower bound strength, cutting the glass presumably resulted in excessive surface or edge damage. Therefore, the data from the $0.219 \times 28.5 \times 28.5$-inch samples is invalid, at least for assessing the strength of naturally weathered glass.

(c) The only sample lot which is valid for assessing the strength of weathered annealed glass is the one containing ten $0.219 \times 28.5 \times 60.5$-inch plates tested with the weathered side in tension.

Figure 12 shows recommended design values for breaking strength versus probability of failure for new annealed plate glass, new annealed sheet and float glass, and weathered annealed glass. It was derived from Figure 11 as follows. For new annealed plate glass the mean of the Figure 11 curves for thicknesses of 0.122 inch, 0.197 inch and 0.373 inch is plotted in Figure 12. The curve for 0.250 -inch thickness is not included in this mean as it is sufficiently different from the other curves to be nonrepresentative of new annealed plate glass. For new annealed sheet glass the mean of all three thicknesses is plotted in Figure 12. As discussed previously, only the curve shown in Figure 11 for the $0.219 \times 28.5 \times 60.5$-inch weathered annealed sheet glass samples tested with weathered side in tension is taken as representative of weathered annealed sheet glass and is reproduced in Figure 12. The curve shown in Figure 11 for $0.125 \times 48 \times 48$-inch tempered float glass is reproduced in Figure 12.

The curve for annealed sheet glass is recommended for annealed float glass also, as the processing would most likely produce the same type of surface flaws. The curve for weathered annealed sheet glass is recommended for all types of weathered annealed glass, including plate, sheet and float glass. At a $1 \%$ probability of failure the total range of breaking strengths for annealed glass plates, regardless of glass type or age, varies only from $3800 \mathrm{lb} / \mathrm{in}^{2}$ to $4000 \mathrm{lb} / \mathrm{in}^{2}$.

The curve for 0.125-inch-thick tempered glass should not be used for thinner tempered glass because of the difficulty of achieving a high level of initial surface compressive stress in glass plates thinner than 0.125 inch. On the other hand the strength of tempered glass plates thicker than 0.125 inch would be somewhat higher than this curve.

\footnotetext{
*Architects generally employ a design breakage rate of 8 per 1000 , $\left(P_{f}=0.8 \%\right)$.
} 


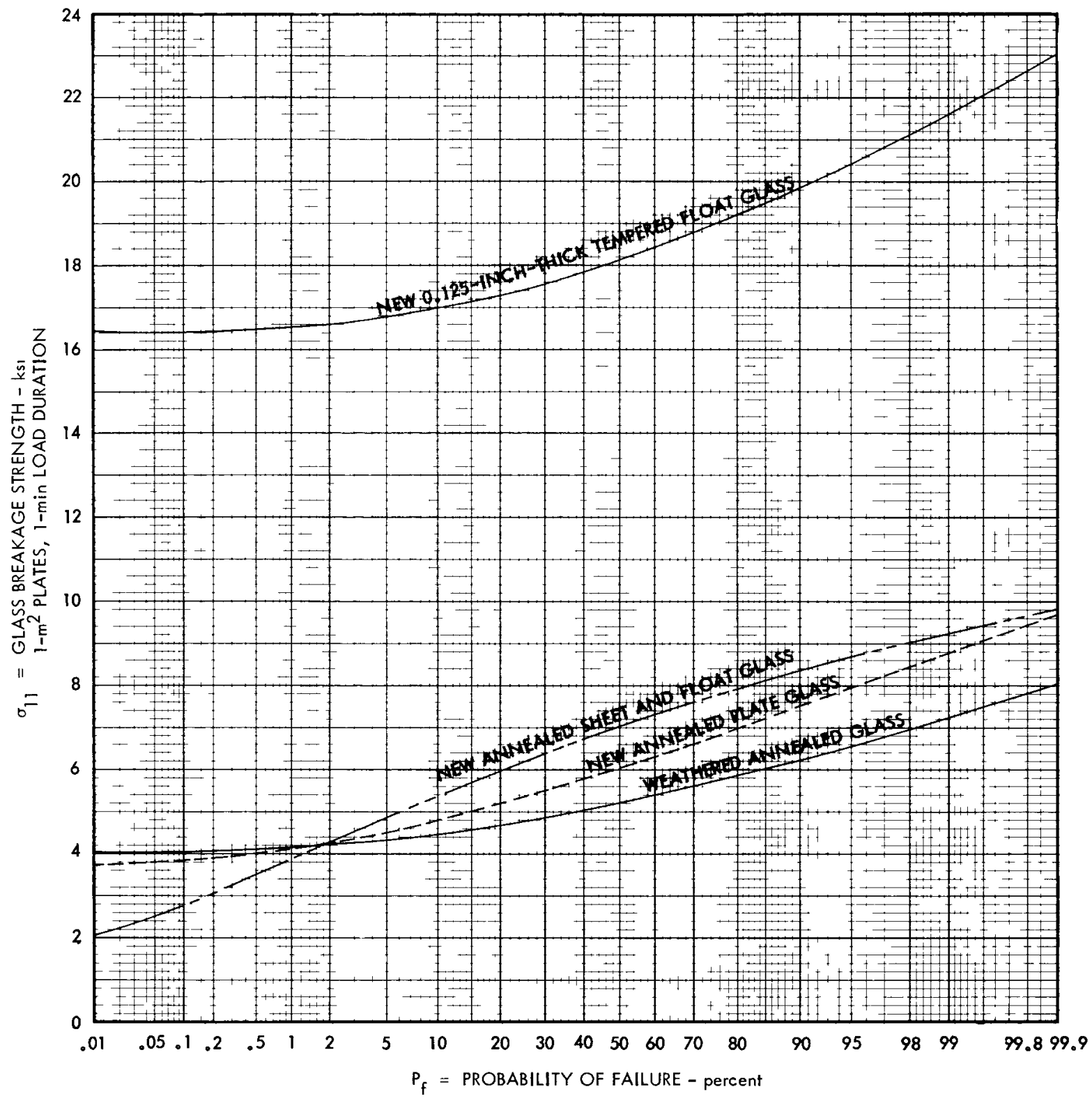

Figure 12. Recommended Design Values for Breakage Strength versus Probability of Failure for $1 \mathrm{~m}^{2}$, Simply Supported, Glass Plates Subjected to a Uniform Normal Pressure Load of 1-Minute Duration 
A rational means of determining the required thickness of a simply supported, rectangular glass plate subjected to environmental loads which may be characterized as uniform normal pressure loads is described in detail in the following pages. The method is outlined below:

(1) Define the various loading conditions (wind, earthquake, snow, deadweight, etc.) appropriate for a given locale using local building codes, or the codes of other advisory or regulatory agencies, such as ANSI A58.1 - 1972 (Reference 18), as applicable.

(2) Determine the stress level corresponding to each of the above loading conditions for an assumed glass thickness.

(3) Determine the allowable stress levels corresponding to each of the above loading conditions. The allowable stresses are a function of the required failure rate, degree of tempering of the glass, surface area of the glass, and duration of the load.

(4) Compare the estimated stresses to the allowable stresses for various load combinations to see if the assumed glass thickness is adequate.

\section{A. DEFINE THE LOADING}

Define the uniform normal pressures associated with wind, snow, deadweight and other loads. The following procedure should be employed:

(1) Using ANSI A58.1 - 1972 (Reference 18) or another code appropriate for the locale, define the various loading conditions in terms of a uniform normal pressure applied to the plate. Thermal loads should also be included if they produce a tensile stress in the glass plate. The designer should consider at least the following loads.

\begin{tabular}{ll} 
Load Description & Pressure \\
\cline { 2 - 2 } Wind & $\mathrm{P}_{\mathrm{W}}$ \\
Earthquake & $\mathrm{P}_{\mathrm{E}}$ \\
Snow & $\mathrm{P}_{\mathrm{S}}$ \\
Deadweight & $\mathrm{P}_{\mathrm{D}}$ \\
Thermal & (Tensile stress in \\
& glass obtained from \\
& other analysis)
\end{tabular}


(2) If the glass plate being analyzed is the only structural member which resists the above loads, skip this section. If, however, the glass plate being analyzed is part of a sandwich structure, it is now necessary to calculate that portion of the load which the glass plate will bear. It should be noted that the normal encapsulant/adhesives typically employed in the manufacture of photovoltaic solar panels do not have sufficient sheer stiffness to cause the top and bottom faces of these sandwich structures to act together as a composite plate. Therefore, the only structural benefit to be derived from such sandwich configurations is that the pressure loads are shared according to the relative stiffness (flexural regidity, D) of the glass plate being analyzed and the other layer(s) of the sandwich. Therefore, the pressure to be applied to the glass plate may be calculated as follows. A typical sandwich-type photovoltaic solar panel is shown in Figure 13 to help illustrate the method of apportioning the pressure loads among the layers of the sandwich.

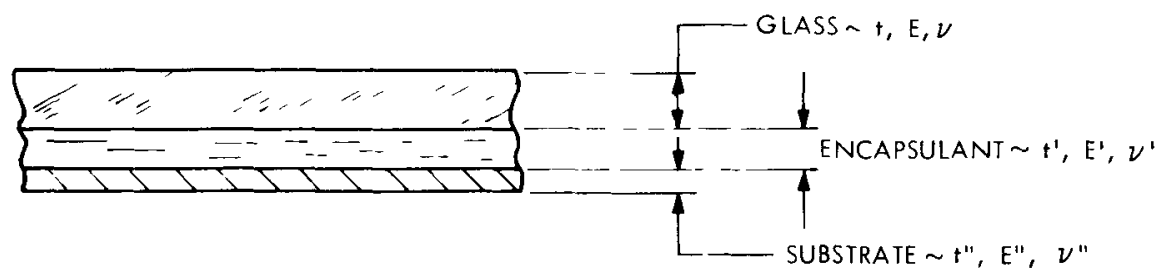

Figure 13. Cross-Section through Typica1 Sandwich-Type Photovoltaic Panel

Calculate the flexural rigidities of the various layers:

Layer

Glass

Encapsulant/ adhesive

Additiona1 loadsharing layers
Flexura1 Rigidity

$$
D=\frac{E t^{3}}{12\left(1-\nu^{2}\right)}
$$

$$
D^{\prime}=\frac{E^{\prime} t^{\prime 3}}{12\left(1-v^{\prime 2}\right)}
$$

(The stiffness of this layer may norma1ly be neglected)

Determine the appropriate fraction of the pressure loads of step Al, $\mathrm{p}^{\prime} / \mathrm{p}$, that should be applied to the glass layer being analyzed.

$$
\frac{\mathrm{P}^{\prime}}{\mathrm{p}}=\frac{\mathrm{D}}{\mathrm{D}+\mathrm{D}^{\prime}+\mathrm{D}^{\prime \prime}+\cdots} \text {. }
$$


Modify the table of loads from step Al to obtain the pressures borne by the glass layer being analyzed:

\begin{tabular}{ll} 
Load Description & Pressure \\
\cline { 2 - 2 } Wind & $\mathrm{P}^{\prime} \mathrm{W}$ \\
Earthquake & $\mathrm{P}^{\prime} \mathrm{E}$ \\
Snow & $\mathrm{P}^{\prime} \mathrm{S}$ \\
Deadweight & $\mathrm{P}^{\prime} \mathrm{D}$ \\
Thermal & (Tensile stress in \\
& glass obtained from \\
& other analysis)
\end{tabular}

B. ESTIMATE THE STRESSES

Now determine the stress levels corresponding to each of the above loading conditions.

(1) Assume a glass thickness, t.

(2) Calculate the "Load Intensity Factor" (LIF) corresponding to each of the above loading conditions. The dimensionless LIF is a function of the loading, and the geometry and material properties of the plate as follows:

$$
L I F=\frac{\mathrm{pb}^{4}}{\mathrm{Dt}}
$$

where

$$
\begin{aligned}
p & =\text { uniform normal pressure } \\
b & =\text { width of plate } \\
t & =\text { thickness of plate } \\
D & =\text { flexural rigidity of plate } \\
& =\frac{E t^{3}}{12\left(1-v^{2}\right)} \\
E & =\text { Young's modulus of plate (use } 10,000,0001 \mathrm{~b} / \mathrm{in}^{2} \\
& \text { for glass) } \\
& =\text { Poisson's ratio of plate (use } 0.22 \text { for glass) }
\end{aligned}
$$

(3) From Figure 7 determine the "Stress Intensity Factor" (SIF) corresponding to the Load Intensity Factor (LIF) for each of the loading conditions of step Al. Note that the SIF is a dimensionless quantity related to the maximum positive principal stress which will occur in the plate. 
The maximum value may occur in either the center of the plate or the corner of the plate depending on the intensity of the loading.

(4) The maximum positive principal stress corresponding to each of the loading conditions is now calculated from the equation

$$
\sigma=\operatorname{SIF} \frac{D}{b^{2} t}
$$

(5) Now construct a table of stresses corresponding to the various loading conditions

Loading

Wind

Earthquake

Snow

Deadweight

Therma $1 *$

\section{Stress}

$\sigma_{W}$

$\sigma_{\mathrm{E}}$

$\sigma_{\mathrm{S}}$

$\sigma_{\mathrm{D}}$

$\sigma_{\mathrm{T}}$

\section{DETERMINE THE ALLOWABLE STRESS FOR GLASS}

The allowable stress for a given loading condition is the breakage stress from Figure 12 taken at an acceptable failure rate and corrected for the surface area of the glass plate being considered and an estimated total load duration for the given loading condition. The allowable stress for a given combined loading condition is the same, except that the allowable stress corresponding to the shortest load duration of the loads being considered is taken as the allowable stress for all loads in the combination. For example, when the combination of wind load (short duration) and deadweight load (1ong duration) is considered, the breakage load associated with the wind load is applied to the combined loading condition.

*The thermal stress (if any) must be determined from a different analysis than that described in this paper. Thermal stresses will exist in the glass if: 1) The glass panel is rigidly mounted to a material with a different thermal expansion coefficient, 2) the glass panels are subjected to local heating, such as will result when part of the panel is shadowed from the sun, and 3) local heating results from damaged solar cells attaining a back-biased condition. During the summer of 1979 Dave Goodwin of JPL studied the stresses due to local heating effects. A general conclusion of his work is that for the third type of local heating effect, one should expect a stress in the glass of $40 \mathrm{lb} / \mathrm{in}^{2}$ to $80 \mathrm{lb} / \mathrm{in}^{2}$ per degree centigrade local temperature gradients in the glass. At this writing, however, no recommendations as to the temperature gradients to be expected are available. 
Determine the breaking stress, $\sigma_{B}$, corresponding to each of the loading conditions identified in step Al. The breaking stress is a function of acceptable failure rate, surface area of the plate, load duration, and degree of temper of the glass (i.e., annealed, semitempered, tempered). The breaking stress, $\sigma_{B}$, is obtained from Equation 11.

$$
\sigma_{B}=\left(f_{A}\right)\left(f_{\tau}\right) \sigma_{11}
$$

where

$$
\begin{aligned}
& \sigma_{11}=\quad \begin{array}{l}
\text { breaking strength of glass for 1-square-meter samples } \\
\text { subjected to a load of } 1 \text { minute total duration. This } \\
\text { strength is a function of the failure rate and glass type } \\
\text { and is obtained from Figure } 12 .
\end{array} \\
& \mathrm{f}_{\mathrm{A}}=\quad \begin{array}{l}
\text { fraction of } \sigma_{11} \text { for a plate area other than } 1 \text { square } \\
\text { meter (obtained from Equation } 7 \text { or Figure } 10 \text { ). }
\end{array} \\
& \mathrm{f}_{\tau}=\begin{array}{l}
\text { fraction of } \sigma_{11} \text { for a load duration other than } 1 \text { minute } \\
\text { for various glass tempers (obtained from Figure } 9 \text { ). }
\end{array}
\end{aligned}
$$

These quantities are determined as follows:

(1) The designer must specify the acceptable failure rate. This should be based on economic considerations; that is, the failure rate which produces the minimum 1 ife-cycle cost for a given application should be used.

(2) From Figure 12 obtain $\sigma_{11}$, the breaking strength for the specified glass type for a 1-square-meter sample subjected to a load of 1-minute total duration corresponding to the failure rate chosen in step (1) above.

(3) The fraction of $\sigma_{11}$ for a plate area other than 1 square meter may be taken from Figure 10 or Equation 7, which may be rewritten as follows:

where

$$
f_{A}=\left(\frac{1}{a \times b}\right)^{1 / 6}
$$

$$
\begin{aligned}
& a=\text { length of plate in meters } \\
& b=\text { width of plate in meters }
\end{aligned}
$$

(4) Next, the designer must estimate the total duration of the loading conditions delineated in step Al. Assume that the design life of a photovoltaic solar panel installation is usually 20 years, and with the exception of deadweight and thermal loads, the loading conditions specified in step Al are expected to occur only once during that period. For these assumptions the following ranges of total load duration may be recommended for the various types of loads. 


\section{Load}

Wind

Earthquake

Snow

Deadweight

Thermal
Tota1 Load Duration

for 20-Year Period

$1 \mathrm{~min}-15 \mathrm{~min}$

$15 \mathrm{sec}-5 \mathrm{~min}$

$12 \mathrm{hr}$ - 3 days

$20 \mathrm{yr}$

2 yr -7 yr

(5) Using Figure 9 and the above load durations, determine the fraction of $\sigma_{11}$ for total load durations other than 1 minute, depending on whether annealed, semi-tempered (i.e., heat strengthened) or tempered glass is being specified for the installation being analyzed. As previously mentioned, this analysis assumes that the glass surfaces are in good condition and have not been subjected to damage or "bruising" such as would be caused by mishandling, hail, impact by rocks, or sandstorms. The designer may interject a degree of conservatism here to cover these possibilities by using load durations as long as or longer than the higher end of the recommended range. Construct a table of load type versus fraction of 1-minute breaking strength as shown:

\begin{tabular}{ll}
\multicolumn{1}{c}{ Load } & $\mathrm{f}_{\tau}$ \\
Wind & $\mathrm{f} W$ \\
Earthquake & $\mathrm{f}_{\mathrm{E}}$ \\
Snow & $\mathrm{f} \mathrm{S}$ \\
Deadweight & $\mathrm{f}$ D \\
Thermal & $\mathrm{f} T$
\end{tabular}

(6) Using Equation 11 and the values of $\sigma_{11}, f_{A}$ and $f_{\tau}$ obtained from steps $\mathrm{C} 2, \mathrm{C} 3$, and $\mathrm{C} 5$, respectively, the following table of load type versus breakage stress may be constructed:

\begin{tabular}{lc}
\multicolumn{1}{c}{ Load } & Breakage Stress \\
Wind & $\sigma_{\mathrm{BW}}$ \\
Earthquake & $\sigma_{\mathrm{BE}}$ \\
Snow & $\sigma_{\mathrm{BS}}$ \\
Deadweight & $\sigma_{\mathrm{BD}}$ \\
Therma1 & $\sigma_{\mathrm{BT}}$
\end{tabular}


D. COMPARE APPLIED STRESS TO GLASS BREAKAGE STRESS

Finally, the stresses due to the applied loads (step B5) are compared to the breaking stresses (step C6) to see if the assumed glass thickness is adequate. The glass thickness is considered adequate if the following combined loading criteria are satisfied. (Remember that for combined loading conditions the breakage stress associatated with the load of shortest duration considered is applied to the combination.) These criteria are essentially equivalent to those in ANSI A58.1 -1972 (Reference 18). The criteria of other codes applicable to a particular installation may be substituted here.

$$
\begin{aligned}
& 1>\frac{\sigma_{\mathrm{D}}}{\sigma_{\mathrm{BD}}} \\
& 1>\frac{\sigma_{D}+\sigma_{L}}{\sigma_{B L}} \\
& 1>\frac{\sigma_{\mathrm{D}}+\left(\sigma_{\mathrm{W}} \text { or } \sigma_{\mathrm{E}}\right)}{\sigma_{\mathrm{BW}} \text { or } \sigma_{\mathrm{BE}}} \\
& 1>\frac{\sigma_{\mathrm{D}}+\sigma_{\mathrm{T}}}{\sigma_{\mathrm{BT}}} \\
& 1>.75\left[\frac{\sigma_{D}+\sigma_{\mathrm{L}}+\left(\sigma_{\mathrm{W}} \text { or } \sigma_{\mathrm{E}}\right)}{\sigma_{\mathrm{BW}} \text { or } \sigma_{\mathrm{BE}}}\right] \\
& 1>.75\left[\frac{\sigma_{\mathrm{D}}+\sigma_{\mathrm{L}}+\sigma_{\mathrm{T}}}{\sigma_{\mathrm{BL}}}\right] \\
& 1>.75\left[\frac{\sigma_{D}+\left(\sigma_{W} \text { or } \sigma_{E}\right)+\sigma_{T}}{\sigma_{B W} \text { or } \sigma_{B E}}\right] \\
& 1>.66\left[\frac{\sigma_{\mathrm{D}}+\sigma_{\mathrm{L}}+\left(\sigma_{\mathrm{W}} \text { or } \sigma_{\mathrm{E}}\right)+\sigma_{\mathrm{T}}}{\sigma_{\mathrm{BW}} \text { or } \sigma_{\mathrm{BE}}}\right]
\end{aligned}
$$

where the "live-load" component, $\sigma_{L}$, is the sum of the tributory live load components, so that

$$
\sigma_{L}=\sigma_{S}+\text { (any other live loads identified) }
$$


The proposed method for determining the thickness of rectangular glass solar collector panels is inherently very accurate. Errors in estimating the applied stress using this method will be canceled, because the same method was used to convert the extensive glass burst pressure data of various investigators to the glass breakage stress values reported herein.

It is hoped that the proposed analytical tool will prove useful to the designer of photovoltaic panel installations which employ glass plates. An immediate need for the method exists in making 1 ife-cycle cost studies; for example, in the cost trade-off between decreasing the glass thickness, which increases the probability of failure and replacement costs, versus the increased first-cost and decreased efficiency associated with specifying thicker glass.

In the preparation of this report the author has been sensitized to certain deficiencies in the proposed method. These deficiencies, noted below, also constitute recommendations for future work.

(1) The actual method of determing the environmental loads is not within the scope of this report. It is apparent, however, that additional aerodynamic studies are needed to determine the flow field and local pressures in large solar array fields. Also, the thermal stresses in photovoltaic solar panels resulting from thermal gradients due to shadowing or other causes should be studied.

(2) Total load durations to be expected over the design life of a photovoltaic panel should be studied further. 
1. Orr, L., Engineering Properties of Glass - Windows and Glass in the Exterior of Buildings, Publication No. 478, Building Research Institute, U.S. National Academy of Sciences, Washington, D.C., 1957.

2. Weiderhorn, S. M., Fracture of Ceramics, Institute for Materials Research, National Bureau of Standards, Washington, D.C., 1969.

3. Dagliesch, W. A., Detailed Comments on Proposed Method for Determining Glass Thickness of Rectangular Solar Collector Panels Subjected to Uniform Normal Pressure Loads, private communication, File Reference No. M43-13-26, National Research Council of Canada, March 30, 1979.

4. Beason, W. L. and Minor, J. E., "A New Approach to the Design of Window Glass for Wind Loading," paper presented at the Second Canadian Workshop on Wind Engineering," September 27-28, 1978.

5. Beason, W. L., Raw data for burst pressure tests of the 20 year old weathered glass plates removed from Great Plain Life Building in Lubbock, Texas, private communication, Texas Technical University, Apri1 1979.

6. Bowles, R. and Sugarman, B., "The Strength and Deflection Characteristics of Large Rectangular Glass Panels Under Uniform Pressure," Glass Technology, Vol. 3 No. 5, October 5, 1962, pp. 156-170.

7. Wilson, A., Data for Burst Pressure Tests of 48 in $x 48$ in $x$ 0.125 in Simply Supported, Tempered Glass Plates, Jet Propulsion Laboratory, Pasadena, California, February 1980.

8. Moore, D. and Wilson, A., Photovoltaic Solar Panel Resistance to Simulated Hail, LSA Task Report No, 5101-62, Jet Propulsion Laboratory, Pasadena, California, 1978.

9. Levy, S., Bending of Rectangular Plates with Large Deflections, Technical Note No. 846, National Advisory Committee for Aeronautics, Washington, D.C., 1942.

10. Kaiser, R., "Rechnerische und experimentelle Ermittlung der Durchbiegungen und Spannungen von quadratischen Platten bei freier Auflagerung an den Randern, gleichmassig verteilter Last und grossen Ausbiegungen." A.f.a.M.M., Bd. 16, Heft 2, April 1936, pp. 73-98.

11. Module/Array Interface Study, Final Report prepared for the Jet Propulsion Laboratory under contract number 954698, Bechtel Corporation, San Francisco, California, August 1978. 
12. Tsai, C., and Stewart, R., "Stress Analysis of Large Deflection of Glass Plates by the Finite Element Method," Journal of the American Ceramic Society, Vo1. 59, No. 9-10, September-October, 1976, Pp. 445-448.

13. Sharifi, P., ARGUS User's Manual, Volume 1, San Jose, California, December 1977 .

14. Brown, W. G., A Practicable Formulation for the Strength of Glass and Its Special Application to Large Plates, National Research Council of Canada, Publication No. NRC 14372, November 1974.

15. Dalgliesh, W. A., "Commentary on the Design of Glass (draft for pub1ic comment)," Canadian Journal of Civil Engineering, 4, 271 , Canada, 1977.

16. Shand, E. B., Glass Engineering Handbook, Mcgraw-Hill Book Company, Inc., New York, 1958.

17. Sines, G. and Irwin, G., Weakest Link Statistics for Fracture, class notes for Engineering Mechanical Properties of Non-Metallic Crystalline Solids, University of California at Los Angeles, January 1974 .

18. ANSI A58.1-1972, American National Standard Building Code Requirements for Minimum Design Loads in Building and Other Structures, American National Standards Institute, Inc., New York, 1972.

19. Hoerner, S. F., Fluid-Dynamic Drag, published by the author, Midland Park, New Jersey, 1965. 
It is desired to determine the required minimum annealed glass thickness for 4-foot-square photovoltaic solar panels to be installed in a large array of photovoltaic panels in Bangor, Maine $\left(45^{\circ} \mathrm{N}\right.$, $\left.39^{\circ} \mathrm{W}\right)$. The panels are to be designed for a 20 -year 1 ife with a $2 \%$ failure rate at design loading conditions. Bangor, Maine was chosen deliberately for this sample problem, as this locality experiences moderately high wind, earthquake and snow loads. The outline scheme used below corresponds to that used in Section VII of this report, METHODOLOGY.

\section{A. DEFINE THE LOADING}

A lengthy discussion on determining the loads using ANSI A58.1 1972 (Reference 18) is included here rather than in Section VII, as the method of determining the loads is not actually within the scope of this document. Furthermore, the designer may wish to use local building codes or other means to define the loads.

(1) Assumed glass thickness $t=.250$ in.

(2) Panel construcion and tilt angle: In addition to the assumed glass thickness of .250 in, it is known that the cells are encapsulated in a .080-in-thick layer of PVB (polyvinylbutyral) and that the substrate is .032-in-thick aluminum.

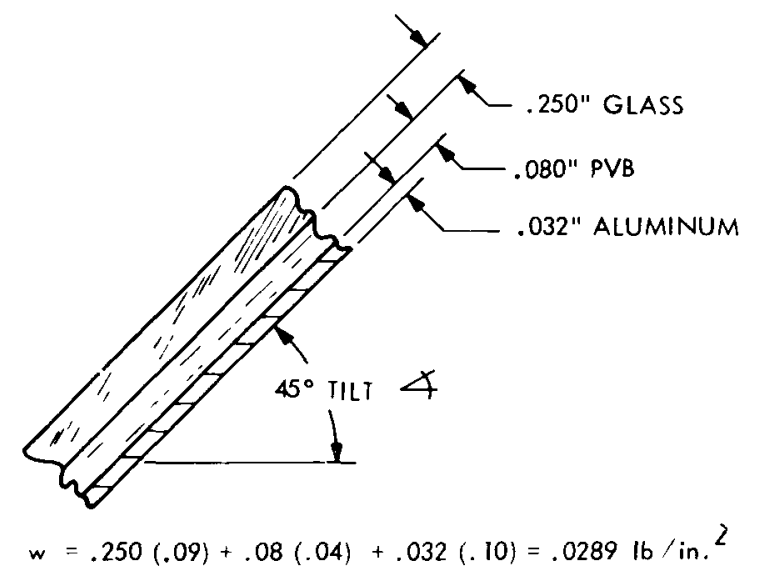

(3) Define the various loading conditions in terms of uniform normal pressures applied to the panel.

Wind Loads. Figure Al of ANSI gives the basic wind speed (measured $30 \mathrm{ft}$ above ground level) for a 25 -year mean recurrence interval at Bangor, Maine as

$$
\mathrm{v}_{30}=70 \mathrm{mph}
$$


ANSI provides additional tables to determine the pressure on signs, roofs, roofs over nonenclosed structures, etc., as a function of the geometry of the structure and the terrain (i.e., city, suburban, and flat, open country). These tables incorporate provisions to increase the dynamic pressure associated with the basic wind speed to account for increased pressure due to wind gusts. The tables in ANSI provide a reasonable means of assessing the pressure acting on photovoltaic panels installed on the roofs of convention buildings. Unfortunately, however, the aerodynamic flow in a large array of photovoltaic panels cannot be compared to any of the standard structures considered in ANSI. Pending a better understanding of the nature of this aerodynamic flow, it seems desirable to derive reasonable, conservative values for the net local pressure acting on a photovoltaic panel by more direct means. This maintains a degree of visibility as to the assumptions included in the derivation of the wind pressure load.

The array in which the 4-ft-square panel is mounted may be considered infinitely long compared to its slant height. Therefore, it is appropriate to employ the following graph (adapted from Hoerner, Reference 19) to determine the net normal force coefficient, $\mathrm{C}_{\mathrm{N}}$.

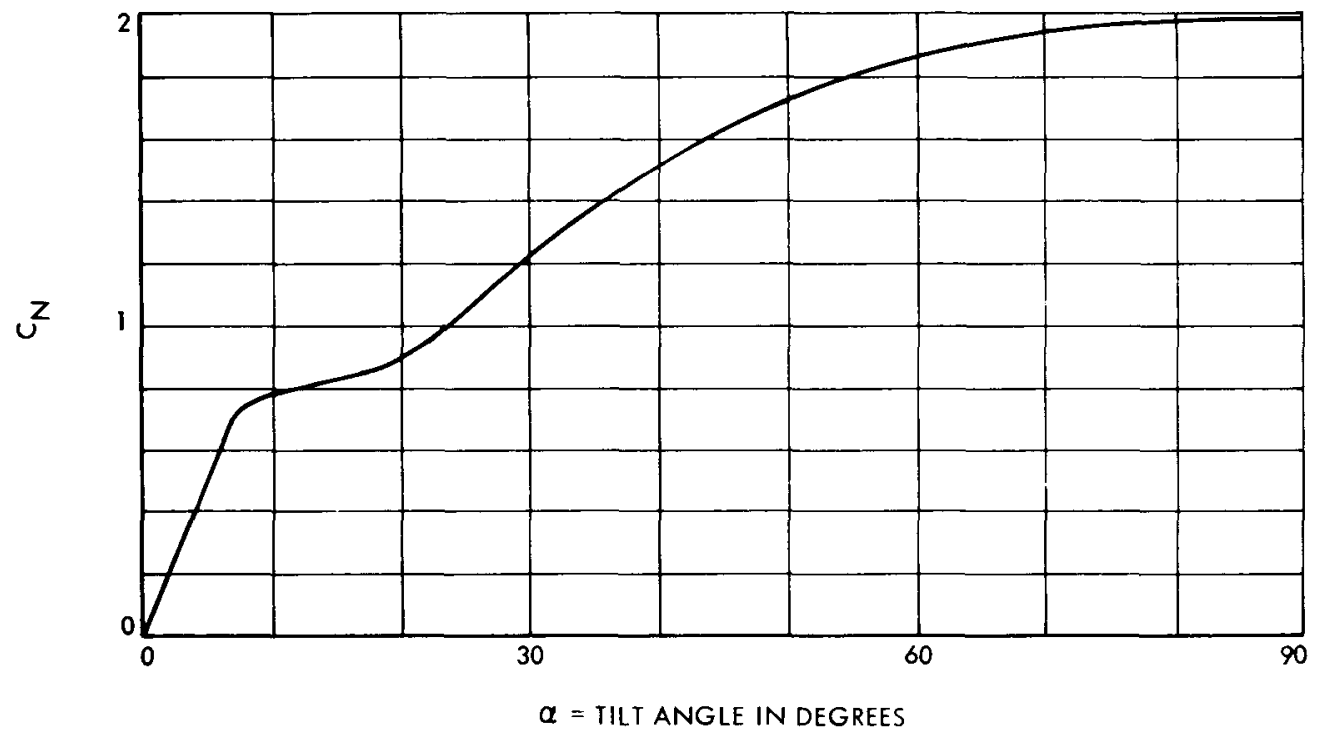

This curve shows how the net normal force coefficient on a panel $\left(c_{N}\right)$ varies with the tilt angle. The local net pressure coefficient, $\mathrm{C}_{\mathrm{PNL}}$, is obtained by multiplying $\mathrm{C}_{\mathrm{N}}$ by 2 based on the following argument. The center of pressure for a two-dimensional plate inclined to the wind is at approximately $1 / 3$ of the chord measured from the windward edge of the plate. A triangular pressure distribution varying from zero at the trailing edge to 2 times $C_{\mathrm{N}}$ at the leading edge will produce an average net normal force coefficient equal to $\mathrm{C}_{\mathrm{N}}$. For this triangular pressure distribution, the center of pressure is at the $1 / 3$ chord.

These considerations result in the following relationship for the net local pressure $P_{W}$ on a photovoltaic panel which is part of a large array:

$$
\mathrm{P}_{\mathrm{W}}=2 \mathrm{C}_{\mathrm{N}} \mathrm{q}_{30}
$$


where

$$
\begin{aligned}
\mathrm{P}_{\mathrm{W}} & =\begin{array}{l}
\text { normal force per unit area due to wind to be shared by } \\
\text { all layers of panel }
\end{array} \\
\mathrm{C}_{\mathrm{N}}= & \text { net normal force coefficient from the figure above } \\
\mathrm{q}_{30}= & \begin{array}{l}
\text { dynamic pressure in } 1 \mathrm{~b} / \mathrm{ft}^{2} \text { corresponding to the } \\
\text { basic wind speed, } \mathrm{V}_{30}
\end{array} \\
= & .00256\left(\mathrm{~V}_{30}\right)^{2}
\end{aligned}
$$

A degree of conservatism is introduced here due to the method of deriving the net local pressure coefficient. Moreover, $q 30$ corresponds to a height of $30 \mathrm{ft}$, and wind velocity is less at heights less than $30 \mathrm{ft}$. On the other hand, the present analysis is unconservative relative to ANSI because it does not include a gust factor. For the sample problem considered here

$$
\mathrm{q}_{30}=\quad .00256(70)^{2}=12.51 \mathrm{~b} / \mathrm{ft}^{2}
$$

and

$$
\mathrm{p}_{\mathrm{W}}=2(1.6)(12.5)=40.01 \mathrm{~b} / \mathrm{ft}^{2}=.2781 \mathrm{~b} / \mathrm{in}^{2}
$$

Earthquake Loads. Equation 17 of ANSI, intended to describe the "1ateral force on parts or portions of buildings or other structures", can be adapted to determine the normal pressure load on the photovoltaic panel as follows:

$$
\begin{aligned}
& \mathrm{P}_{\mathrm{E}}=\mathrm{ZC}_{\mathrm{P}} \mathrm{w} \\
& P_{E}=\text { normal force per unit area of panel surface to be } \\
& \text { shared by all layers of the panel } \\
& \mathrm{Z}=\text { numerical coefficient depending on the zone as } \\
& \text { determined from Figure A8 (ANSI) } \\
& \text { Zone } \quad \text { Z } \\
& 1 \quad .25 \\
& 2 \quad .50 \\
& 3 \quad 1.00
\end{aligned}
$$

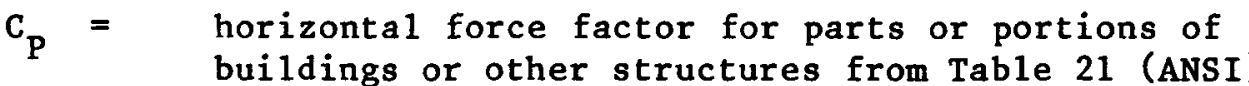

$$
\begin{aligned}
& \mathrm{w}=\text { panel weight per unit area as calculated in A2 above }
\end{aligned}
$$


For this application

$$
\begin{aligned}
& \mathrm{Z}=.50(\text { from Figure A8 }- \text { ANSI }) \\
& \mathrm{C}_{\mathrm{P}}=.2(\text { from Table } 21-\text { ANSI }) \\
& \mathrm{w}=.0289(\text { from step A2 above) }
\end{aligned}
$$

So that

$$
\mathrm{p}_{\mathrm{E}}=(.5)(.2)(.0289)=.002891 \mathrm{~b} / \mathrm{in}^{2}
$$

Snow Loads. ANSI provides maps with isolines of ground snow load in pounds per square foot for 25, 50, and 100-year mean recurrence intervals. For structures having no human occupants or where there is negligible risk to human life, the 25 -year mean recurrence interval (Figure A7-ANSI) may be used. To find the normal pressure loads on the photovoltaic panels due to snow, the ground snow load is multiplied by a coefficient, $\mathrm{C}_{S}$, which depends on the tilt angle, $\alpha$. The total pressure on the panel due to snow is

$$
\mathrm{PS}_{\mathrm{S}}=\mathrm{C}_{\mathrm{S} \mathrm{P}_{\mathrm{GS}}}
$$

where

$$
\begin{aligned}
& \mathrm{P}_{\mathrm{S}}=\begin{array}{l}
\text { normal force per unit area of panel surface to be } \\
\text { shared by all layers of the panel }
\end{array} \\
& \mathrm{C}_{\mathrm{S}}=\text { snow load coefficient } \\
& \frac{\frac{\alpha}{30^{\circ}}}{\frac{\mathrm{C}_{S}}{70^{\circ}}} \\
& 30^{\circ}-70^{\circ} \\
& 0
\end{aligned}
$$

$\mathrm{P}_{\mathrm{GS}}=\begin{aligned} & \text { basic ground snow load for } 25 \text {-year mean recurrence } \\ & \text { interval }\end{aligned}$

For the present application

$$
\begin{aligned}
& \mathrm{C}_{\mathrm{S}}=\quad .8-\frac{45-30}{50}=.5 \\
& \mathrm{p}_{\mathrm{GS}}=\quad 521 \mathrm{~b} / \mathrm{ft}^{2} \text { (from Figure A7 - ANSI for Bangor, ME }\left(45^{\circ} \mathrm{N}, 399^{\circ}\right) \text { ) } \\
& \left(\mathrm{p}_{\mathrm{s}}\right)_{\text {total }}=.5(52)=261 \mathrm{~b} / \mathrm{ft}^{2}=.181 \mathrm{lb} / \mathrm{in}^{2}
\end{aligned}
$$


Deadweight Loads. The normal pressure on the panel due to gravity loading is obtained from the following equation:

$$
\mathrm{P}_{\mathrm{D}}=\mathrm{w} \cos \alpha
$$

For this application

$$
\begin{aligned}
P_{D} & =.0289 \cos 45^{\circ} \\
& =.02041 \mathrm{~b} / \mathrm{in}^{2}
\end{aligned}
$$

Thermal Loads. Thermal loading results when temperature variations through the thickness, or over the surface of the glass induce thermal stresses. The method of defining the thermal loads for a particular panel design and application is not considered here.

The total pressure loads to be shared by all of the layers of the panel are summarized as follows:

\section{Load Description}

Wind

Earthquake

Snow

Deadweight

\section{Pressure $\left(1 \mathrm{~b} / \mathrm{in}^{2}\right)$}

$$
\begin{aligned}
& \mathrm{P}_{\mathrm{W}}=.278 \\
& \mathrm{P}_{\mathrm{E}}=.002 \\
& \mathrm{P}_{\mathrm{S}}=.181 \\
& \mathrm{P}_{\mathrm{D}}=.020
\end{aligned}
$$

(4) Next it is necessary to determine that portion of the above pressure loads which the glass layer must bear. The cross-section of the sample problem panel is shown below:

$$
\begin{array}{lll}
\text { Glass } & t=.250 \mathrm{in} ., & E=10,000,0001 \mathrm{~b} / \mathrm{in}^{2}, v=.22 \\
\text { PVB } & t=.080 \mathrm{in} ., E=3001 \mathrm{~b} / \mathrm{in}^{2}, v=.25 \\
\text { Aluminum } & t=.032 \mathrm{in.}, E=10,000,0001 \mathrm{~b} / \mathrm{in}^{2}, v=.33
\end{array}
$$

The flexural rigidities (D) of the various layers are

Layer

Glass

PVB

Aluminum

Tota1

$$
D=\frac{E t^{3}}{12\left(1-v^{2}\right)}
$$

13680

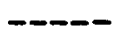

30 
Therefore, the fraction of the total pressure loads borne by the glass layer is

$$
\frac{p^{\prime}}{p}=\frac{13680}{13710}=.998
$$

The table of total pressure loads from step A3 should be modified to obtain the pressures borne by the glass layer:

Load

Wind

- Earthquake

Snow

Deadweight
Pressure $\left(1 \mathrm{~b} / \mathrm{in}^{2}\right)$

.277

.002

.180

.020

B. ESTIMATE THE STRESSES

Now calculate the load intensity factor (LIF), find the corresponding stress intensity factor (SIF), and the stress corresponding to each of the above loading conditions.

$$
\begin{aligned}
& \mathrm{b}=48 \mathrm{in} \\
& \mathrm{t}=.250 \mathrm{in} \\
& \mathrm{E}=10,000,000 \mathrm{1b} / \mathrm{in}^{2} \\
& \nu=.22 \\
& \mathrm{D}=\frac{\mathrm{Et}^{3}}{12\left(1-\nu^{2}\right)}=13680
\end{aligned}
$$

$\underline{\text { Load }}$

$$
L I F=\frac{\mathrm{pb}^{4}}{\mathrm{Dt}}
$$

430

3

279

31

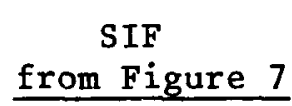

94

1

69

9
$\sigma=\operatorname{sIF} \frac{D}{b^{2} t}(p s i)$

2230

20

1640

Deadweight

$--$
210

$500 *$

*Methods to calculate thermal stress are not included here. This value is assumed in order to see the affect on the calculations which follow. 
C. GLASS BREAKAGE STRESS

(1) For a failure rate of $2 \%$

$$
\mathrm{P}_{\mathrm{f}}=.02
$$

(2) From Figure 12 we obtain the breaking strength of a 1-square-meter sample of annealed float glass subjected to a load of 1-minute duration

$$
\sigma_{11}=4200
$$

(3) The fraction which may be used for a $4 \mathrm{ft}(1.22 \mathrm{~m})$ square plate is

$$
\mathrm{f}_{\mathrm{A}}=\left(\frac{1}{1.22 \times 1.22}\right)^{1 / 6}=.936
$$

(4) Next we estimate the total duration of the loads for a design life of 20 years. Remember that wind, earthquake, and snow loads are obtained from ANSI for a 25-year mean recurrence interval. For these loads, then, it remains only to estimate the duration of loading for one occurrence during the 20-year design 1ife. The deadweight load acts during the entire life of the panel. The thermal load will obviously occur daily and may vary in intensity seasonally. Therefore, the total duration of the thermal load is probably in the range of $1 / 10$ to $1 / 3$ of the design life of the panel. The following table shows the total duration of the various loads, using values at the high end of the range recommended in section VII, step C4.

Load

Wind

Earthquake

Snow

Deadweight

Therma1*
Tota1 Load Duration for 20-Year Life

(5) Using Figure 9 for semi-tempered glass, construct the following table of load type versus $f_{\tau}$, the fraction of the 1-minute, 1-square-meter breaking strength of annealed glass which may be used for other load durations. 
Load

Wind

Earthquake

Snow

Deadweight

Therma1
.82

.88

.62

.51

.52

(6) Finally, the $2 \%$ failure rate breakage stress for a $4 \mathrm{ft} x$ $4 \mathrm{ft}$ panel of semi-tempered glass may be obtained from Equation 11 for each of the load conditions considered:

$$
\sigma_{\mathrm{B}}=\mathrm{f}_{\mathrm{A}} \mathrm{f}_{\tau} \sigma_{11}
$$

For the sample problem

$$
\begin{aligned}
\sigma_{B} & =.936 \mathrm{f}_{\tau} 4200 \\
& =3930 \mathrm{E}_{\tau}
\end{aligned}
$$

The following table may now be constructed:

Load

$$
\sigma_{B}=3930 \mathrm{f}_{\tau}\left(1 \mathrm{~b} / \mathrm{in}^{2}\right)
$$

for $2 \%$ Failure Rate
Wind

3220

Earthquake

Snow

Deadweight

Thermal
3460

2440

2000

2040

D. COMPARE APPLIED STRESS TO GLASS BREAKAGE STRESS

The combined load criteria given in Section VII D must be satisfied.
$\frac{\sigma_{\mathrm{D}}}{\sigma_{\mathrm{BD}}}$
$=\quad \frac{210}{2000}$
$=.11<1$
$\frac{\sigma_{\mathrm{D}}+\sigma_{\mathrm{S}}}{\sigma_{\mathrm{BS}}}$
$=\frac{210+1640}{2440}$
$=.76<1$
$\frac{\sigma_{\mathrm{D}}+\sigma_{\mathrm{W}} \text { or } \sigma_{\mathrm{E}}}{\sigma_{\mathrm{BW}} \text { or }_{\sigma_{\mathrm{BE}}}}$
$=\frac{210+2230}{3220}$
$=.76<1$ 


$$
\begin{aligned}
& \frac{\sigma_{D}+\sigma_{T}}{\sigma_{B T}} \\
& =\quad \frac{210+500}{2040} \\
& =.35<1 \\
& .75\left[\frac{\sigma_{\mathrm{D}}+\sigma_{\mathrm{S}}+\left(\sigma_{\mathrm{W}} \text { or } \sigma_{\mathrm{E}}\right)}{\sigma_{\mathrm{BW}} \text { or } \sigma_{\mathrm{BE}}}\right] \\
& =.75\left[\frac{210+1640+2230}{3220}\right] \\
& =.95<1 \\
& .75\left[\frac{\sigma_{D}+\sigma_{S}+\sigma_{T}}{\sigma_{B S}}\right] \\
& =.75\left[\frac{210+1640+500}{3220}\right] \\
& .75\left[\frac{\sigma_{\mathrm{D}}+\left(\sigma_{\mathrm{W}} \text { or } \sigma_{\mathrm{E}}\right)+\sigma_{\mathrm{T}}}{\sigma_{\mathrm{BW}} \text { or } \sigma_{\mathrm{BE}}}\right] \\
& =.75\left[\frac{210+2230+500}{3220}\right] \\
& .66\left[\frac{\sigma_{\mathrm{D}}+\sigma_{\mathrm{S}}+\left(\sigma_{\mathrm{W}} \text { or } \sigma_{\mathrm{E}}\right)+\sigma_{\mathrm{T}}}{\sigma_{\mathrm{BW}} \text { or } \sigma_{\mathrm{BE}}}\right]=.66\left[\frac{210+1640+2230+500}{3220}\right]=.94<1
\end{aligned}
$$

The assumed thickness of .250 in. may be considered adequate for this application. 
To automate the "best-fit" Weibull analysis of brittle fracture data, a FORTRAN computer program was written by Robert Weaver of the Jet Propulsion Laboratory. A listing and sample output of this program follows.

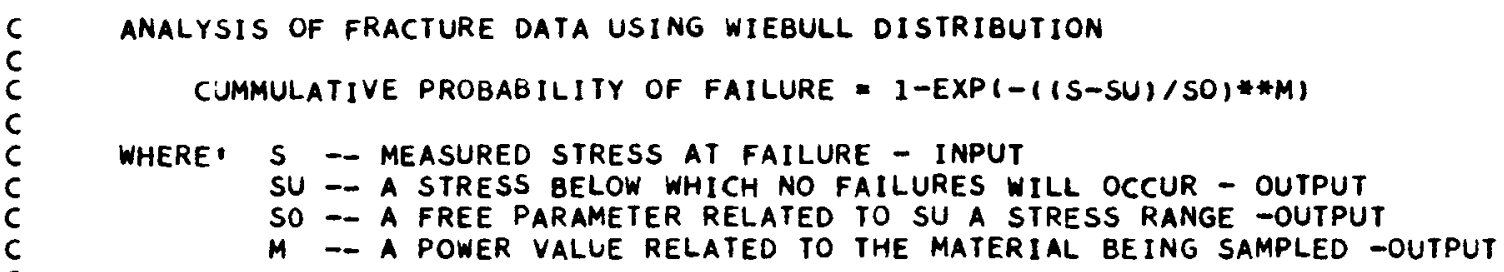

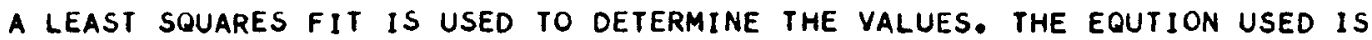
LOG1O(LOGIO(1/1-CPF) = MLOG1O(S-SU)-MLOGIO(SO)-.3622156

WHICH IS ANALOGOUS TO $Y=A X+B$ WHERE.

$$
A=M, B=-M L O G 10(S O)-.3622156(-.3622156=\text { LOGIOLOG1O(E)) }
$$

USING THE INPUTS OF STRESS AT FAILURE, S(I) AND THE NUMBER THAT FAILED AT THAT STRESS, FIII AND VARYING SU TO OBTAIN A FIT CORRELATION AS CLOSE TO I AS POSSIBLE THE PARAMETERS CAN BE DETERMINED

DIMENSION S(200) ,A(200),B(200),SL(200),SO(200),DF(200),

*FS(200), TTL(12),FL(200),FLC(200)

INTEGER $F(200), T G$

DATA TTL/12*:

REAL *8 CC $(200), 5 C C$

$F F=.3622156$

1 CALL INPT (TTL,S,F,N)

C

SORT THE INPUT FROM SMALLEST TO LARGEST

$N M=N-1$

$K=2$

DO $15 \quad I=1, N M$

DO $10 \mathrm{~J}=\mathrm{K}, \mathrm{N}$

IF $(S(I) \cdot L T \cdot S(J))$ GO TO 10

$T S=S(1)$

$S(I)=S(J)$

$S(J)=T S$

$T G=F(I)$

$F(I)=F(J)$

$F(J)=T G$

10 CONTINUE

$K=K+1$

15 CONTINUE

$T E=0$

$D S U=S(1) / 200$.

DO $20 \quad I=1, N$

$20 T G=T G+F(I)$

TOTS $=T G+1$.

$F S(1)=F(1) / T O T S$

$F L(1)=A L O G) O(A L O G 10(1 \cdot 1(1 \cdot-F S(1)))$

DO $30 \quad I=2, N$

$F S(1)=F S(1-1)+F(1) /$ TOTS

$G=A L O G 1 O(A L O G) O(1, /(1 \cdot-(F S(1) / 1 \cdot)))$

$F L(I)=G$

30 CCNTINUE

SSU $=-D S U$

DO $40 \quad I=1.200$

$S S U=S S U+D S U$

CALL FIT (SSU,SB,SA,SCC,FL,S,N)

IFISSU.GT.S(I)) GO TO 4 I

$A(I)=S A$

$B(I)=S B$ 


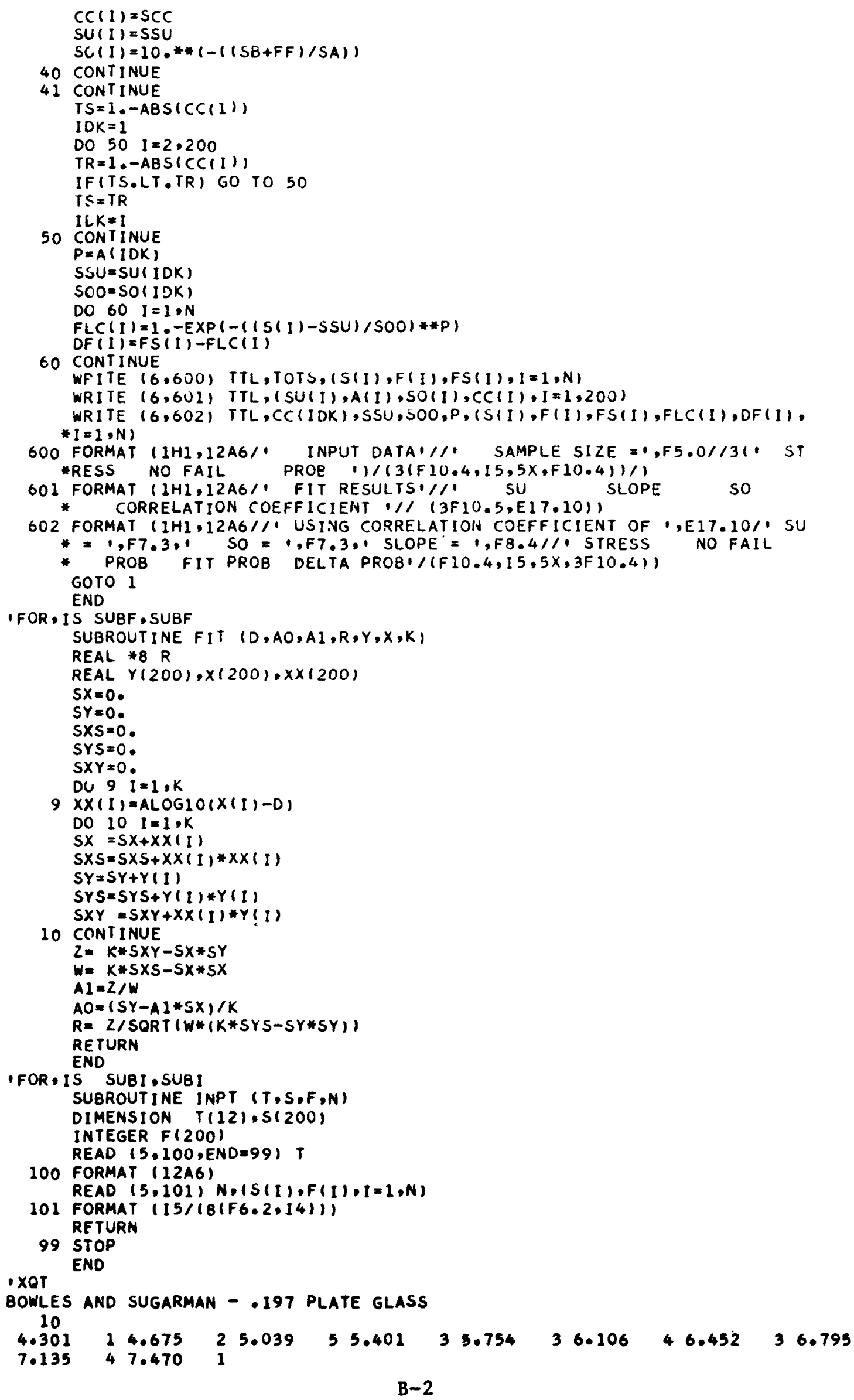


BOWLES AND SUgARMAN - .197 PLATE gLASS INPUT DATA

SAMPLE SIZE = 31.

$\begin{array}{lcccccccc}\text { STRESS } & \text { NJ FAIL } & \text { PROB } & \text { STRESS } & \text { NO FAIL } & \text { PROB } & \text { STRESS } & \text { NO FAIL PROB } \\ 4.3010 & 1 & .0323 & 4.6750 & 2 & .0968 & 5.0390 & 5 & .2581 \\ 5.4010 & 3 & .3548 & 5.7540 & 3 & .4516 & 6.1060 & 4 & .5806 \\ 6.4520 & 3 & .6774 & 6.7950 & 4 & .8065 & 7.1350 & 4 & .9355 \\ 7.4700 & 1 & .9677 & & & & & & \end{array}$

BOWLES AND SUGARMAN - .197 PLATE GLASS

FIT RESULTS

\begin{tabular}{|c|c|c|c|}
\hline SU & SLOPE & so & CORRELATION COEFFICIENT \\
\hline 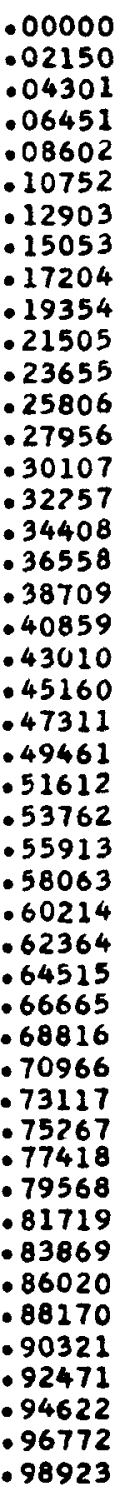 & $\begin{array}{l}7.74879 \\
7.71961 \\
7.69039 \\
7.66120 \\
7.63199 \\
7.60278 \\
7.57356 \\
7.54435 \\
7.51514 \\
7.48592 \\
7.45666 \\
7.42742 \\
7.39818 \\
7.36892 \\
7.33966 \\
7.31041 \\
7.28113 \\
7.25184 \\
7.22257 \\
7.19326 \\
7.16398 \\
7.13466 \\
7.10535 \\
7.07602 \\
7.04669 \\
7.01737 \\
6.98802 \\
6.95867 \\
6.92932 \\
6.89996 \\
6.87059 \\
6.84121 \\
6.81182 \\
6.78243 \\
6.75302 \\
6.72361 \\
6.69419 \\
6.66476 \\
6.63531 \\
6.60588 \\
6.57641 \\
6.54695 \\
6.51747 \\
6.48799 \\
6.45850 \\
6.42900 \\
6.39949\end{array}$ & $\begin{array}{l}6.25482 \\
6.23304 \\
6.21127 \\
6.18949 \\
6.16770 \\
6.14592 \\
6.12413 \\
6.10234 \\
6.08055 \\
6.05876 \\
6.03696 \\
6.01516 \\
5.99336 \\
5.97156 \\
5.94976 \\
5.92795 \\
5.90614 \\
5.88433 \\
5.86251 \\
5.84070 \\
5.81888 \\
5.79706 \\
5.77523 \\
5.75341 \\
5.73158 \\
5.70974 \\
5.68791 \\
5.66607 \\
5.64423 \\
5.62239 \\
5.60054 \\
5.57869 \\
5.55684 \\
5.53499 \\
5.51313 \\
5.49127 \\
5.46941 \\
5.44754 \\
5.42567 \\
5.40380 \\
5.38192 \\
5.36004 \\
5.33816 \\
5.31628 \\
5.29439 \\
5.27249 \\
5.25060\end{array}$ & 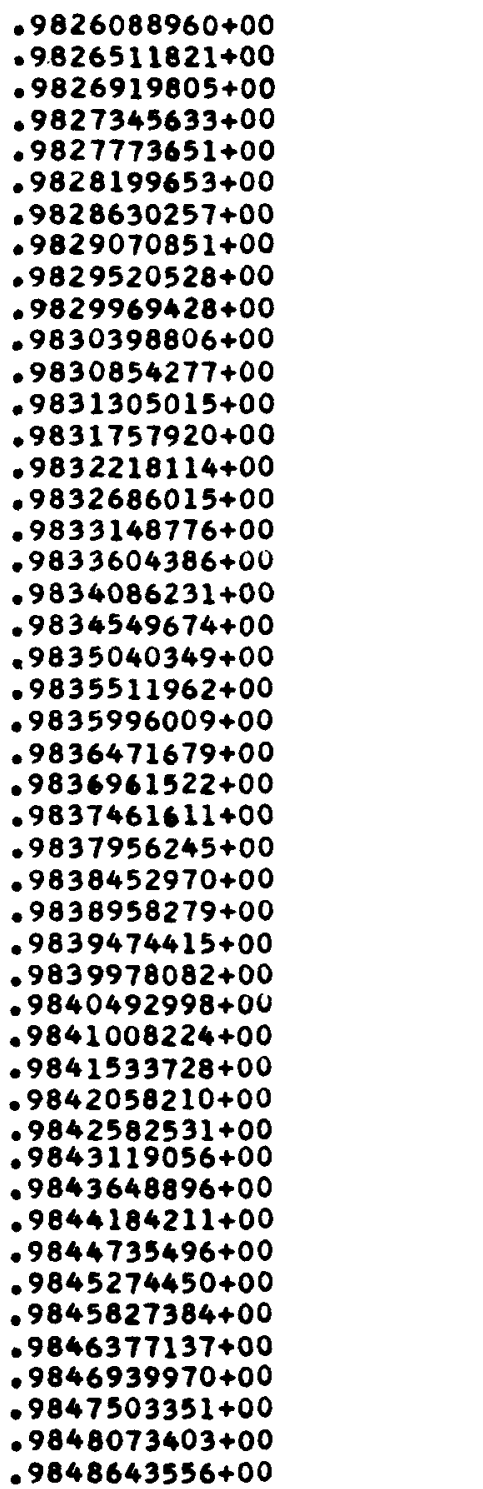 \\
\hline
\end{tabular}




\begin{tabular}{|c|c|c|c|}
\hline 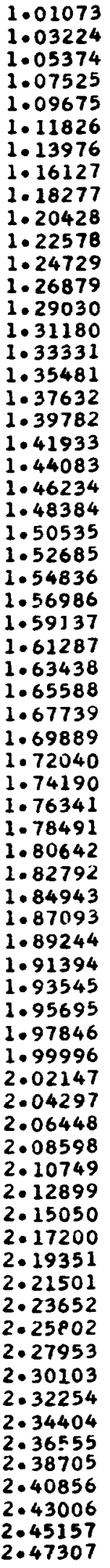 & 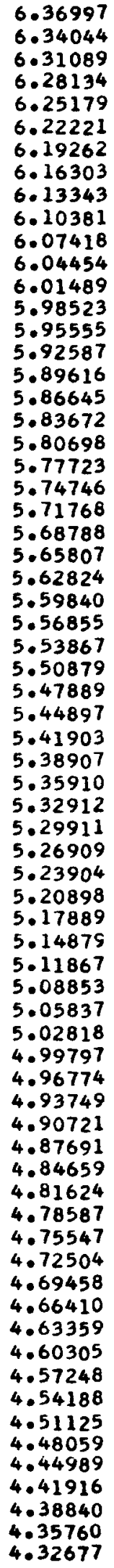 & 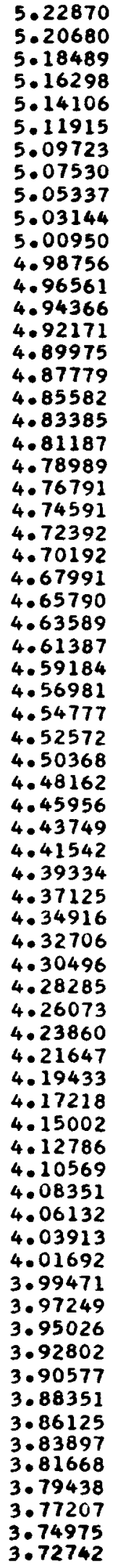 & 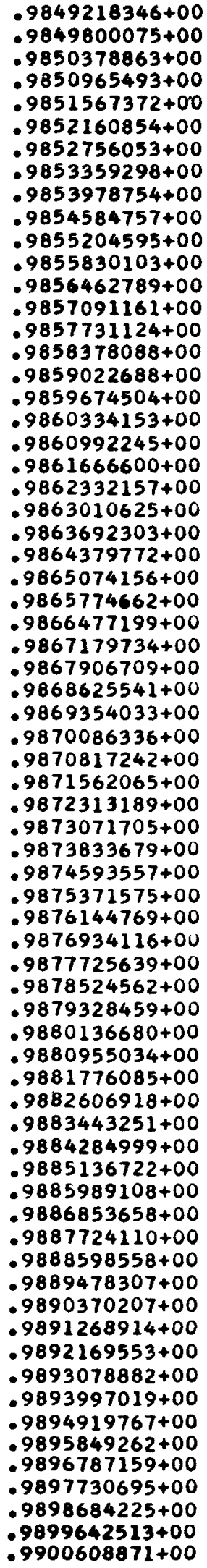 \\
\hline
\end{tabular}




\begin{tabular}{|c|c|c|c|}
\hline 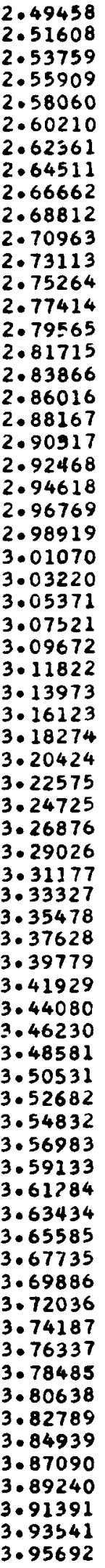 & 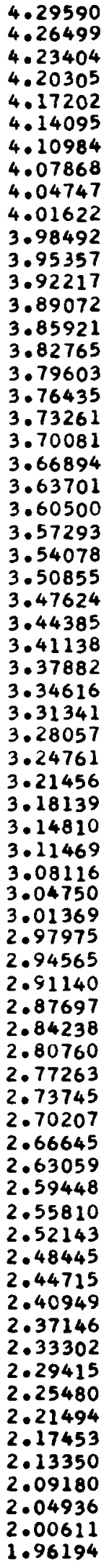 & 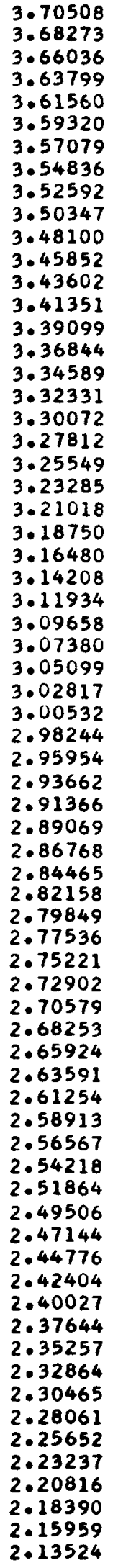 & 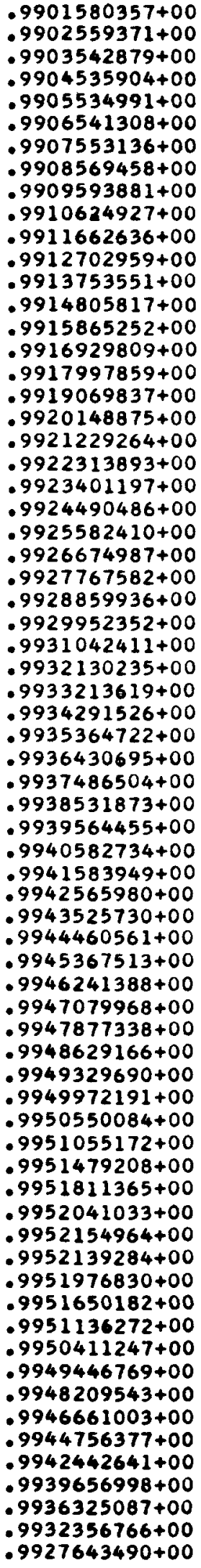 \\
\hline
\end{tabular}




$\begin{array}{llll}3.97842 & 1.91675 & 2.11084 & .9922052438+00 \\ 3.99993 & 1.87042 & 2.08641 & .9915420016+00 \\ 4.02143 & 1.82277 & 2.06196 & .9907541233+00 \\ 4.04294 & 1.77361 & 2.03751 & .9898157370+00 \\ 4.06444 & 1.72271 & 2.01309 & .9886936416+00 \\ 4.08595 & 1.66977 & 1.98873 & .9873443398+00 \\ 4.10745 & 1.61439 & 1.96450 & .9857098778+00 \\ 4.12896 & 1.55605 & 1.94049 & .9837108586+00 \\ 4.15046 & 1.49407 & 1.91683 & .9812353388+00 \\ 4.17197 & 1.42744 & 1.89376 & .9781191662+00 \\ 4.19547 & 1.35470 & 1.87166 & .9741091457+00 \\ 4.21498 & 1.27352 & 1.85127 & .9687873500+00 \\ 4.23648 & 1.17981 & 1.83408 & .9613913861+00 \\ 4.25799 & 1.06521 & 1.82386 & .9502896941+00 \\ 4.27949 & .90646 & 1.83421 & .9307063476+00\end{array}$

BOWLES AND SUgARMAN - 197 PLATE GLASS

\begin{tabular}{|c|c|c|c|c|c|c|}
\hline $\begin{array}{l}\text { USING COR } \\
\text { SU }=3 .\end{array}$ & & $\begin{array}{r}\text { ATION } \\
\text { SO }\end{array}$ & $\begin{array}{l}\text { COEFFICIENT } \\
=\quad 2.471 \mathrm{~S}\end{array}$ & $\begin{array}{l}\text { OF } \\
\text { LOPE }\end{array}$ & $\begin{array}{r}.99 \\
=\quad 2\end{array}$ & $\begin{array}{l}2154964+0 \\
5214\end{array}$ \\
\hline TRESS & No & FAIL & PROB & FIT & PROB & DELTA PROB \\
\hline $\begin{array}{l}4.3010 \\
4.6750 \\
5.0390 \\
5.4010 \\
5.7540 \\
6.1060 \\
6.4520 \\
6.7950 \\
7.1350 \\
7.4700\end{array}$ & & $\begin{array}{l}1 \\
2 \\
5 \\
3 \\
3 \\
4 \\
3 \\
4 \\
4 \\
1\end{array}$ & $\begin{array}{l}.0323 \\
.0968 \\
.2581 \\
.3548 \\
.4516 \\
.5806 \\
.6774 \\
.8065 \\
.9355 \\
.9677\end{array}$ & & $\begin{array}{l}.0333 \\
.1016 \\
.2066 \\
.3402 \\
.4841 \\
.6241 \\
.7447 \\
.8392 \\
.9464 \\
.9495\end{array}$ & $\begin{array}{r}-.0010 \\
-.0048 \\
.0515 \\
.0146 \\
-.0324 \\
-.0435 \\
-.0672 \\
-.0328 \\
.0291 \\
.0182\end{array}$ \\
\hline
\end{tabular}

